
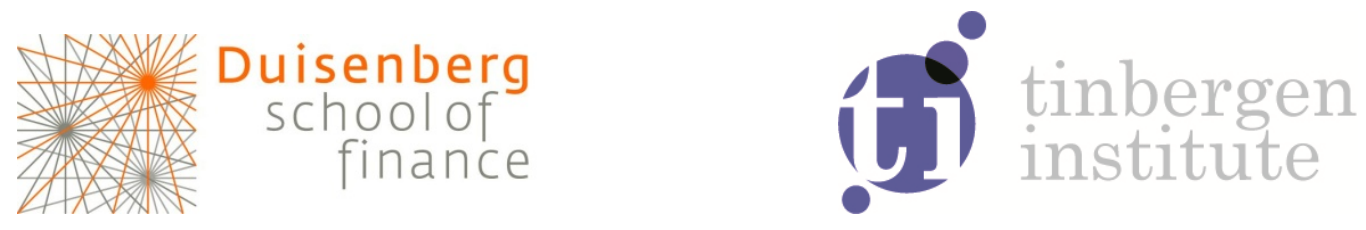

Duisenberg school of finance - Tinbergen Institute Discussion Paper

TI 12-140/ DSF 46/IV

\title{
Aggregate Stock Market Illiquidity and Bond Risk Premia
}

Kees E. Bouwman'

Elvira Sojlil,2

Wing Wah Tham ${ }^{1,3}$

${ }^{1}$ Erasmus School of Economics, Erasmus University Rotterdam;

2 Duisenberg school of finance;

3 Tinbergen Institute. 
Tinbergen Institute is the graduate school and research institute in economics of Erasmus University Rotterdam, the University of Amsterdam and VU University Amsterdam.

More TI discussion papers can be downloaded at http://www.tinbergen.nl

Tinbergen Institute has two locations:

Tinbergen Institute Amsterdam

Gustav Mahlerplein 117

1082 MS Amsterdam

The Netherlands

Tel.: +31(0)205251600

Tinbergen Institute Rotterdam

Burg. Oudlaan 50

3062 PA Rotterdam

The Netherlands

Tel.: +31(0)10 4088900

Fax: +31(0)104089031

Duisenberg school of finance is a collaboration of the Dutch financial sector and universities, with the ambition to support innovative research and offer top quality academic education in core areas of finance.

DSF research papers can be downloaded at: http://www.dsf.nl/

Duisenberg school of finance

Gustav Mahlerplein 117

1082 MS Amsterdam

The Netherlands

Tel.: +31(0)20 5258579 


\title{
Aggregate Stock Market Illiquidity and Bond Risk Premia
}

\author{
Kees E. Bouwman \\ Erasmus University Rotterdam \\ Elvira Sojli \\ Erasmus University Rotterdam and Duisenberg school of finance \\ Wing Wah Tham \\ Erasmus University Rotterdam and Tinbergen Institute
}

\begin{abstract}
We assess the effect of aggregate stock market illiquidity on U.S. Treasury bond risk premia. We find that the stock market illiquidity variable adds to the well established Cochrane-Piazzesi and Ludvigson-Ng factors. It explains $10 \%, 9 \%, 7 \%$, and $7 \%$ of the one-year-ahead variation in the excess return for two-, three-, four-, and five-year bonds respectively and increases the adjusted $R^{2}$ by $3-6 \%$ across all maturities over Cochrane and Piazzesi (2005) and Ludvigson and Ng (2009) factors. The effects are highly statistically and economically significant both in and out of sample. We find that our result is robust to and is not driven by information from open interest in the futures market, long-run inflation expectations, dispersion in beliefs, and funding liquidity. We argue that stock market illiquidity is a timely variable that is related to "flight-to-quality" episodes and might contain information about expected future business conditions through funding liquidity and investment channels.
\end{abstract}

Keywords: Market liquidity; Bond risk premia; Flight-to-quality.

JEL Classification: G10; G20; G14. 


\section{Introduction}

Business cycles and macroeconomic information are important determinants of the term structure of interest rates and bond risk premia. Recent papers have shown that aggregate stock market illiquidity is a robust predictor of business cycles and macroeconomic information (e.g. Næs, Skjeltorp, and Ødegaard, 2011). Motivated by this empirical evidence, we examine whether aggregate stock market liquidity can explain U.S. Treasury bond risk premia. We use the Amihud (2002) illiquidity measure, the average illiquidity ratio across all stocks, to examine whether stock market illiquidity can predict excess bond returns. ${ }^{1}$ We also use the difference between the aggregated illiquidity of large and small cap stocks as an alternative variable, and we find that it is an especially strong predictor of bond premia. Stock market illiquidity displays strong forecasting power for excess returns across bonds of all maturities. It explains up to 10\%, $9 \%$, $7 \%$, and $7 \%$ of the one-year-ahead variation in the excess return for two-, three-, four-, and five-year bonds, respectively. The magnitude of the predictability that we find using aggregate stock market illiquidity is not only statistically but also economically significant. We find that one standard deviation increase in the aggregate illiquidity of the stock market leads to an increase of 45 basis points in bond risk premia.

Our paper joins other empirical research documenting predictability in the excess returns of U.S. Treasury bonds. Cochrane and Piazzesi (2005) show that a linear combination of five forward spreads can forecast excess bond returns. Ludvigson and $\mathrm{Ng}$ (2009) and Cooper and Priestley (2009) find that macroeconomic variables contain information about future excess bond returns and argue that their findings are related to the premia demanded by investors due to macroeconomic uncertainty. Moreover, Joslin, Priebsch, and Singleton (2010) show the importance of real economic activity and inflation on market prices of level, slope, and curvature risks in the U.S. Treasury market. In a more recent paper, Duffee (2011) finds a latent component of bond risk premia that contains substantial information about expected yields and is negatively correlated with aggregate economic activity.

Following the literature, we always condition on the well-established Cochrane and Piazzesi (2005) and Ludvigson and Ng (2009) factors. While the Cochrane and Piazzesi (2005) factor subsumes variables like forward spreads, yield spreads, and yield factors, the Ludvigson and

\footnotetext{
${ }^{1}$ This measure is the same used in Næs et al. (2011) and is kindly provided by Johannes Skjeltorp.
} 
$\mathrm{Ng}$ (2009) factor focuses on factors outside the bond market and contains information from 132 measures of economic and financial activities, which include dividend yield, TED spread, credit spread, S\&P500 returns. The single illiquidity variable contains additional information about bonds' expected returns that is not present in these factors, and it increases the adjusted $R^{2}$ by $3-6 \%$ across all bond maturities over the Cochrane and Piazzesi (2005) and Ludvigson and $\mathrm{Ng}$ (2009) factors. In addition, stock market illiquidity has strong out-of-sample forecasting power for excess bond returns above the existing factors. Our results are robust to accounting for the small-sample properties of the data and to using different tests of forecasting accuracy. The in- and out-of-sample results remain quantitatively and qualitatively the same when we investigate the impact of stock illiquidity on monthly returns of portfolios of Treasury bills and bonds as in Duffee (2012). Furthermore, we find that our result is robust to and is not driven by information from open interest in the futures market (Hong and Yogo, 2012), longrun inflation expectations (Cieslak and Povala, 2011), and dispersion in beliefs (Buraschi and Whelan, 2012). The additional information of aggregate stock market illiquidity on bond risk premia for all maturities is remarkable and surprising.

There can be four potential explanations for our findings. The first is that aggregate stock market illiquidity is acting as a proxy for bond market illiquidity, see Goyenko and Ukhov (2009). We control for bond market illiquidity in our predictive regressions and find that it does not explain bond risk premia above stock market illiquidity. In addition, the sheer magnitude of stock market illiquidity's economic significance, 45 annual basis points, is related to bond risk premia beyond the price of future bond liquidity and beyond systematic bond liquidity risk in the treasury market. For example, Goldreich, Hanke, and Nath (2005) find that the yield difference between on- and off-the-run securities is less than 2 basis points and show the existence of a price premium for liquidity in the U.S. treasury market. Li, Wang, $\mathrm{Wu}$, and $\mathrm{He}$ (2009) focus on the pricing of systematic liquidity in the treasury market and find an annual premium of 9 basis points for a difference of 10 percentage points in systematic liquidity risk.

Second, stock market illiquidity can be related to bond risk premia through the channel of asymmetric information. Albuquerque, De Francisco, and Marques (2008) present a model of market-wide private information that is useful for trading across a variety of assets and argue that this private information is related to discount rates and future cash flows that fluctuate with economy-wide business conditions. They show that this information from the U.S. equity market 
forecasts industry stock returns and currency returns. Brennan, Huh, and Subrahmanyam (2011) consider the Amihud (2002) illiquidity measure as a noisier version of Kyle (1985)'s measure of price impact. They argue that the Amihud illiquidity measure increases when trading on private information increases. Thus, stock market aggregate illiquidity might contain market-wide private information. To investigate the asymmetric information hypothesis, we include the market-wide information variables from Albuquerque et al. (2008) in the predictive regressions. ${ }^{2}$ Consistent with Albuquerque et al. (2008), we find that market-wide private information variables predict excess bond returns but do not affect the predictive power of our variable. We do not find support for asymmetric information as a driver of our results.

Third, stock market illiquidity can be related to "flight-to-quality" and can contain information about the uncertainty of investors' preferences (see Gallmeyer, Hollifield, and Seppi, 2005; Saar, 2006). Gallmeyer et al. (2005) theoretically show that investors' information asymmetry about each other's preferences can explain the empirical relation between stock market illiquidity and future returns. In their model, learning through trading, demand discovery, leads to market liquidity becoming a forward looking proxy for risk preferences in future prices. The model can generate "flight-to-quality"-like volume and price characteristics under some model parameters. From an alternative perspective, Baker and Stein (2004) theoretically relate the predictability of returns by market liquidity and flight to quality through information asymmetry regarding future cash flows, short sale constraints, and irrational investors.

Following Longstaff (2004), we use mutual fund flows as a measure of "flight-to-quality". We find that changes in stock market illiquidity are related to shifts of U.S. mutual fund flows from equity to money market mutual funds. An increase in illiquidity is positively correlated with flows into money market mutual funds and negatively correlated with flows to equity mutual funds, indicating its connection to flight to quality. In an alternative exercise, we find that stock market illiquidity explains and predicts changes in the average proportional holding of equities and bonds by balanced/hybrid mutual funds. Flight-to-quality episodes are associated with increases in the implied volatility index, and Bekaert, Hoerova, and Duca (2010) suggest that the implied volatility index is a proxy for risk aversion and market uncertainty. We find that stock market illiquidity is contemporaneously associated with and predictive of changes in the implied volatility index (VXO).

\footnotetext{
${ }^{2}$ The data, from 1993 to 2003, on market-wide private information is kindly provided by Rui Albuquerque.
} 
Fourth, stock market illiquidity can matter due to the funding illiquidity channel. Stock market illiquidity affects or is affected by the macro economy and investments in the real economy, as shown in the monetary model with liquidity of Kiyotaki and Moore (2008). In the model, investing entrepreneurs need to sell their holdings of liquid assets and equity to finance investments because of borrowing constraints. Thus a negative shock to asset resaleability (stock market liquidity) can reduce the amount of an entrepreneur's down payment, which will result in large and persistent reductions in investment, output, and employment. Anticipating higher market illiquidity, equity prices fall because entrepreneurs hold more liquid assets in their portfolios as they flee to liquidity. Eisfeldt (2005) also attempts to theoretically link endogenous liquidity and returns of risky assets and shows that low productivity leads to lower investment in risky assets and thus decreases liquidity. To investigate the relation between stock market illiquidity and investments, we use our illiquidity variable to forecast real investment growth. We find that stock market illiquidity has a positive relation with investment and can explain real investment growth up to four quarters ahead, consistent with Næs et al. (2011). Thus we cannot rule out the investment hypothesis.

Brunnermeier and Pedersen (2009) show that the liquidity spiral effects of funding and market liquidity can have an important impact on the real economy, as observed in the recent financial crisis. In a recent survey, Brunnermeier, Eisenbach, and Sannikov (2012) argue that liquidity risk can amplify a small exogenous shock into a sizable shock and into an endogenous risk in the macro economy. Fontaine and Garcia (2012) is the first paper to empirically show that funding liquidity conditions affect the term structure of U.S. sovereign bonds. They use the funding liquidity factor in predictive regressions of off-the-run excess bond returns. Although we investigate the information content of stock market illiquidity for on-the-run excess bond returns, our result is consistent with Fontaine and Garcia (2012), if one considers the endogenous relation between market and funding liquidity in the spirit of Brunnermeier and Pedersen (2009).

As the flight-to-quality and funding liquidity channel are not mutually exclusive, we study these channels jointly by including flight-to-quality (mutual fund flows and VXO) and funding liquidity (Fontaine and Garcia, 2012) variables into the excess bond return predicting equations. ${ }^{3}$ We find that the inclusion of stock market illiquidity, funding liquidity, and an interaction term of the two subsume the information in all the flight-to-quality variables. The findings

\footnotetext{
${ }^{3}$ We are grateful to Jean-Sébastien Fontaine for providing us with his funding liquidity data.
} 
provide empirical evidence that supports the theoretical relation between funding and market illiquidity as well as their impact on asset risk premia. However, our results suggest that stock market illiquidity contains additional information beyond the flight-to-quality and funding liquidity channel, because the stock market illiquidity variable remains significant after controlling for VXO, mutual fund flows, and funding liquidity. This result might come from the timely availability of the market illiquidity variable relative to other excess bond return predictors.

The paper proceeds as follows. Section I positions the paper in the existing literature. Section II presents the econometric framework. Section III discusses the data and preliminary analysis. Section IV presents results on the link between stock market illiquidity and bond premia and the yield curve, and Section V shows the robustness analysis. Section VI discusses the potential channels that relate aggregate stock market illiquidity to excess bond returns. Section VII concludes.

\section{Literature Review and Contribution}

Our paper contributes to the recent literature on bond return predictability, which is embedded in the debate about the validity of the expectation hypothesis. The earlier literature relates excess bond returns to yield spreads and provides evidence that the $n$-year spread of the $n$ year forward rate and the one-year yield (Fama and Bliss, 1987) and the treasury yield spreads (Campbell and Shiller, 1991) can forecast excess bond returns. Extending the findings of Fama and Bliss (1987), Cochrane and Piazzesi (2005) find that a single factor constructed from a linear combination of five forward spreads predicts up to $44 \%$ of the variation in excess bond returns. ${ }^{4}$

The more recent literature focuses on information from macroeconomic variables. Ludvigson and Ng (2009) and Cooper and Priestley (2009) show that macroeconomic variables predict excess bond returns through the cyclical nature of the risk premia. A series of recent papers by Chernov and Mueller (2012), Cieslak and Povala (2011), Joslin et al. (2010), Huang and Shi (2011), and Buraschi and Whelan (2012) support the findings on the relation of macroeconomic variables and business cycles with risk premia. Duffee (2011) also finds a latent component

\footnotetext{
${ }^{4}$ However, Thornton and Valente (2012) find that one-year excess return forecasts using long-term forward rates do not add economic value relative to the expectations hypothesis. Duffee (2011) also reports that half of the variation in bond risk premia cannot be explained by the cross section of bond yields.
} 
of bond risk premia that contains substantial information about expected future yields and is negatively correlated with aggregate economic activity. Cieslak and Povala (2011) argue that long-run inflation expectations contain important information about bond risk premia. Buraschi and Whelan (2012) study the link between macroeconomic disagreement and the bond market. They show that belief dispersion about the real economy, inflation, and yields predict excess bond returns. Mueller, Vedolin, and Zhou (2011) show that the market variance risk premium has strong predictive power at the one-month horizon, however the predictive power disappears for longer horizons (one year and above). These recent developments in the literature suggest the importance of considering factors outside bond yields in understanding the drivers behind term structure dynamics.

Our paper contributes to the existing bond risk premia literature by showing that stock market illiquidity contains information about future excess bond returns even after controlling for information from bond yields, forward rates, macroeconomic, and dispersion in beliefs variables. Unlike these papers, we consider the role of aggregated stock market illiquidity motivated by the Næs et al. (2011)'s finding that stock market illiquidity is a robust predictor of business cycles. We go a step further by establishing that market illiquidity can affect bond risk premia via either the investment channel or as a timely variable that captures investors' time-varying risk aversion and the uncertainty of their preferences. Thus, we provide empirical support for macroeconomic models with financial frictions and for market microstructure models with endogenous liquidity.

One important related paper is Fontaine and Garcia (2012). They argue that funding liquidity conditions affect the prices of U.S. sovereign bonds. Fontaine and Garcia (2012) use the price differentials of treasury securities with similar cash flows but different ages to construct a funding liquidity variable. They use the funding liquidity factor in predictive regressions of off-the-run excess bond returns. Their results highlight the importance of the funding market for fixed-income markets. However, we use the information content of stock market illiquidity for on-the-run excess bond returns, and our result is complementary to Fontaine and Garcia (2012), in the light of the endogenous relation between market and funding liquidity in the spirit of Brunnermeier and Pedersen (2009). Thus our findings provide empirical support for the interaction between liquidity in security markets and funding conditions of financial intermediaries. 
Furthermore, we contribute to the literature that theoretically relates stock and bond markets, see Koijen, Lustig, and Nieuwerburgh (2009) and Lettau and Wachter (2011). Our findings provide empirical evidence that suggests that stock market variables are important in understanding asset prices in bond markets, which could be useful for future theoretical literature focusing on the joint modeling of stock and bond returns.

\section{Econometric Framework of Bond Return Regressions}

Let $p_{t}^{(n)}$ denote the log-price in year $t=1, \ldots, T$ of an $n$-year zero-coupon bond. The log yield on this bond is defined as $y_{t}^{(n)}=-\frac{1}{n} p_{t}^{(n)}$. The log one-year forward rate at time $t$ of a loan from time $t+n-1$ to $t+n$ is then defined by $f_{t}^{(n)}=p_{t}^{(n-1)}-p_{t}^{(n)}$. The log excess return of holding an $n$-year zero-coupon bond from time $t$ to $t+1$ is given as $r x_{t+1}^{(n)}=p_{t+1}^{(n-1)}-p_{t}^{(n)}-y_{t}^{(1)}$. The predictable component in the excess bond return reflects a bond risk premium. Under the expectations hypothesis, there is no predictability in excess returns and hence the bond risk premium is constant. However, recent empirical evidence shows predictable variation in excess bond returns, which implies a time-varying bond risk premium.

We adopt the standard approach to uncover predictable variation in excess bond returns by regressing excess bond returns on a vector of predictor variables, $\boldsymbol{X}_{t}$ :

$$
r x_{t+1}^{(n)}=\beta_{0}+\boldsymbol{\beta}_{1}^{\prime} \boldsymbol{X}_{t}+\varepsilon_{t+1}^{(n)}
$$

To examine the link between bond risk premia and stock market illiquidity, we run regressions with different sets of predictor variables, including liquidity measures. We consider the predictor variables identified by Cochrane and Piazzesi (2005) and Ludvigson and Ng (2009) to explore whether stock market illiquidity contains additional information over the existing factors in explaining bond excess returns.

Cochrane and Piazzesi (2005) regress excess returns of two- to five-year maturity bonds on a constant and five forward rates and find that a single tent-shaped linear combination of the five forward rates, the CP-factor, explains between $30 \%$ and $35 \%$ of the variation in excess bond returns. The CP-factor is constructed by pooling the regressions for the individual maturities:

$$
\overline{r x}_{t+1}=\gamma_{0}^{C P}+\gamma_{1}^{C P^{\prime}} \boldsymbol{X}_{t}^{C P}+\bar{\varepsilon}_{t+1}^{C P},
$$


where $\overline{r x}_{t+1}=\frac{1}{4} \sum_{n=2}^{5} r x_{t+1}^{(n)}$ and $\boldsymbol{X}_{t}^{C P}=\left[y_{t}^{(1)}, f_{t}^{(2)}, \ldots, f_{t}^{(5)}\right]$. The CP-factor combines the information in all forward rates and is defined as $C P_{t}=\widehat{\gamma}_{0}^{C P}+\widehat{\gamma}_{1}^{C P^{\prime}} \boldsymbol{X}_{t}^{C P}$. We use both the five forward rates and the $\mathrm{CP}$ factor as predicting variables in the bond risk premia regressions.

Ludvigson and $\mathrm{Ng}$ (2009) examine the link between bond risk premia and macroeconomic fundamentals by regressing excess bond returns on several macro factors. Instead of selecting specific macro variables, they use dynamic factor analysis to extract nine macroeconomic factors from a panel of 132 measures of economic activity. These factors are used as predictor variables in bond excess return regressions. We control for the predictive information in macro variables by including the full set of nine macro factors identified Ludvigson and $\mathrm{Ng}$ (2009). In addition, we also combine the nine macro factors into a single forecasting factor by using the regression:

$$
\overline{r x}_{t+1}=\gamma_{0}^{L N}+\gamma_{1}^{L N^{\prime}} \boldsymbol{X}_{t}^{L N}+\bar{\varepsilon}_{t+1}^{L N},
$$

where $\boldsymbol{X}_{t}^{L N}=\left[L N F_{1, t}, \ldots, L N F_{9, t}\right]$ contains the nine macro factors of Ludvigson and $\mathrm{Ng}(2009)$. We define the single forecasting factor, the LN-factor, as $L N_{t}=\widehat{\gamma}_{0}^{L N}+\widehat{\gamma}_{1}^{L N^{\prime}} \boldsymbol{X}_{t}^{L N}$.

Following the literature, each month we construct one-year-ahead bond excess returns, because a purely yearly sample would have too few observations. Thus, the bond return regressions are estimated over a sample of monthly data, which include overlapping one-year excess return observations. Overlapping data complicate regression inference because they lead to autocorrelated residuals. Following Cochrane and Piazzesi (2005), we compute standard errors using the Newey-West procedure with 18 lags to account for heteroscedasticity and autocorrelation in the residuals.

The Newey-West standard errors are based on asymptotic approximations that might be inadequate in finite samples. We, therefore, use a bootstrap analysis to check for the robustness of our inference in finite samples. In particular, we test for the significance of our variables of interest in the bond return regression (1) by constructing bootstrap samples for both $\boldsymbol{X}_{t}$ and $r x_{t+1}^{(n)}$. The bootstrap procedure is described in Appendix A.

\section{A Out-of-sample Forecasting}

Out-of-sample forecasts are constructed by using a moving window of 15 years (i.e. 180 monthly observations). Using this window, we first estimate the Cochrane-Piazzesi and Ludvigson- $\mathrm{Ng}$ 
( $C P$ and $L N$ hereafter) factors, in order to avoid including information not available at the time of the forecast to the econometrician. Next, we estimate the regressions over the sample window of 180 observations. We obtain forecasts of the one-year ahead excess returns from the estimated regression. For the next observation, the window is shifted one month ahead. So the first window runs from January 1964 to December 1978 and is used to forecast the excess bond return for the period January to December 1979. The second window runs from February 1964 to January 1979 and is used to forecast the excess bond return for the period February 1979 to January 1980.

Using the forecasts, we compute the one-step-ahead prediction errors that would prevail under two competing models and test which model makes larger errors on average. More specifically, we compare the out-of-sample forecasting ability of the model with liquidity variables as a predictor in addition to the $\mathrm{CP}$ and LN factors to the benchmark forecasting model that contains only the CP and LN factors.

We compare the prediction errors of two different forecasting models by the ratio of Root Mean Squared Errors (RMSEs), the Clark and West (2007) and the Giacomini and White (2006) tests for predictive ability. The Clark-West (CW) test considers the null hypothesis of equal predictive ability by comparing mean squared prediction errors of two forecasting methods, applied to nested models. We use the standard normal distribution to obtain approximate $p$ values for the $\mathrm{CW}$ test. The unconditional version of the Giacomini-White $(\mathrm{GW})$ test is also a test of equal predictive ability that compares mean squared prediction errors. The test statistic of the GW test coincides with that of the Diebold and Mariano (1995) test, but the tests use different null hypotheses. The GW test explicitly accounts for parameter uncertainty in the formulation of the null hypothesis.

\section{Data}

Following the literature, we use end-of-month data on U.S. Treasury bonds from the FamaBliss data set available from the Center for Research in Security Prices (CRSP) to construct excess bond returns and forward rates. The data set contains constant-maturity yields for the one, two, three, four, and five year maturities. The sample contains monthly data for the period January 1964 to December 2008. This is a longer sample compared to the one used by 
Cochrane and Piazzesi (2005) and Ludvigson and Ng (2009) and includes the recent financial crisis. We construct annual returns by continuously compounding monthly return observations. Data on the macro factors of Ludvigson and Ng (2009) are obtained from the website of Sydney Ludvigson. ${ }^{5}$

\section{A Aggregate Stock Market Illiquidity Factor}

In the literature, there are many different measures of liquidity constructed from daily and intraday data. Intraday data is only available starting from 1993. Given the need for a long time series in our analysis, we use measures that can be calculated using daily data. Goyenko, Holden, and Trzcinka (2009) show that low frequency measures of liquidity are good approximations for high frequency measures of spreads and price impact. In addition, we need to use variables that yield relatively stable measures of liquidity at the monthly level. The Lesmond, Ogden, and Trzcinka (1999) measure (LOT) and the Roll (1984) implicit spread estimator are very noisy and unreliable, when constructed using only a month of daily data. They are more appropriate for quarterly analysis. ${ }^{6}$ Like Næs et al. (2011), we use the Amihud (2002) illiquidity ratio (ILR) which is provided by Johannes Skjeltorp. ILR is calculated as $\frac{1}{N} \sum_{t=1}^{N}\left(\left|r_{t}\right| / V O L U M E_{t}\right)$, where $\left|r_{t}\right|$ is the daily absolute return, $V O L U M E_{t}$ is the daily total dollar volume, and $N$ is the number of trading days in a month. When $I L R$ is large, market illiquidity is high.

ILR is calculated using stock prices, returns, and trading volume from CRSP. Only common shares listed on the NYSE are included. For each stock the ILR is calculated daily and averaged across the month and then averaged across all securities to create a market-wide measure. Also, we use the difference between the ILR of small and large stocks, represented by the bottom and top quartile respectively, ILRSMB. The liquidity measures at the monthly level exhibit unit roots. We take the yearly change in log illiquidity to be consistent with the bond risk premia literature $^{7}$, i.e. for time $t$ in months we define:

$D_{12} I L R_{t}=\log I L R_{t}-\log I L R_{t-12}$,

$D_{12} I L R S M B_{t}=\left(\log I L R_{\text {small }, t}-\log I L R_{\text {large }, t}\right)-\left(\log I L R_{\text {small }, t-12}-\log I L R_{\text {large }, t-12}\right)$.

\footnotetext{
${ }^{5}$ http://www. econ.nyu.edu/user/ludvigsons/, as of April 15, 2011. See Ludvigson and Ng (2009) for details on the underlying macro series and the construction of the factors.

${ }^{6}$ In addition, Næs et al. (2011) show that the predictive ability of aggregate stock market illiquidity is the same when using different measures of illiquidity using quarterly data.

${ }^{7}$ There are several ways to deal with non-stationarity and the method that we use is only one way to transform the data. We also use a trend and exponential smoothing to transform ILR and find similar results.
} 
A positive change in ILR implies a decrease in liquidity. A positive change in ILRSMB implies an increasing gap between the liquidity of small and large stocks.

\section{B Preliminary Analysis}

Table 1 presents the sample characteristics for all the variables and their correlations. The mean and median $D_{12} I L R$ are highly negative. This implies that stock market liquidity has improved on average over the sample period. The mean and median $D_{12} I L R S M B$ are positive, implying an increase in the liquidity gap between small and large stocks during the sample period. Large stocks have benefited more from overall liquidity improvements than small stocks.

Liquidity deterioration in the stock market is associated with positive bond premia. The correlation of the equally-weighted bond excess returns with stock market illiquidity factors is higher than with many of the other factors. Stock market illiquidity variables are positively correlated with all the forward rates and most of the Ludvigson and Ng factors. The correlations with these factors are not very large, implying that stock market illiquidity might have additional information to these variables already identified in the literature. Also, $D_{12} I L R$ and $D_{12} I L R S M B$ are highly correlated to each other.

Figure 1 presents the fluctuations in the equally-weighted bond excess returns one year ahead, the CP and LN factors, and the stock market illiquidity factors. The CP and LN factors co-move substantially with the average bond excess return. $D_{12} I L R S M B$ seems to move more in sync with the average bond excess return than $D_{12} I L R$. 


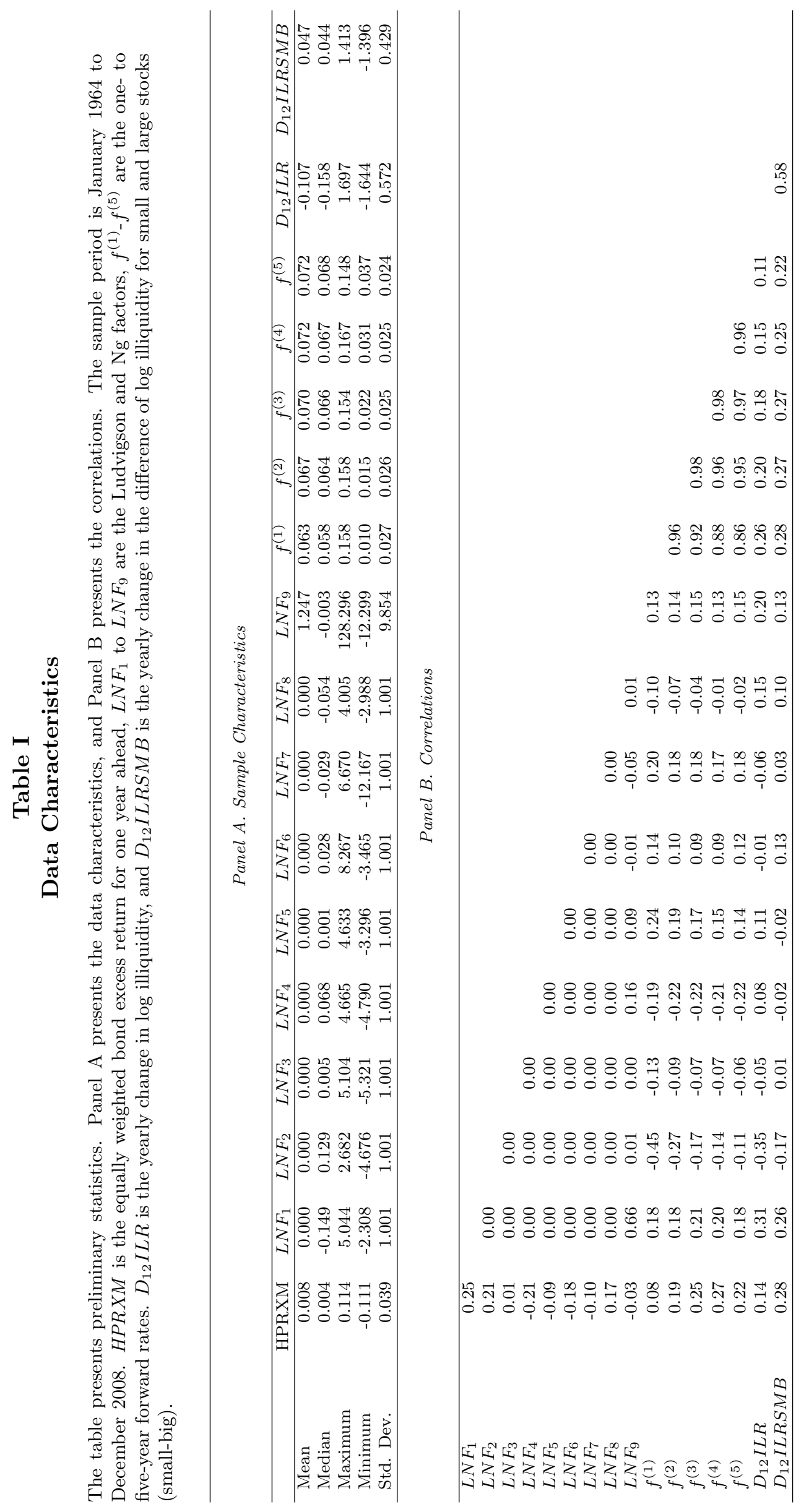


Figure 1

\section{Average Annual Excess Bond Returns and Explanatory Factors}

The figure presents the average annual excess bond return, $\overline{r x}_{t}$ return and forecasts from explanatory factors, factors. The explanatory factors are: the Cochrane-Piazzesi factor $C P_{t}$ in Panel (a), the Ludvigson-Ng factor $L N_{t}$ in Panel (b), the stock market illiquidity factor $D_{12} I L R$ in Panel (c), and the stock market illiquidity factor $D_{12} I L R S M B$ in Panel (d).

(a) Cochrane-Piazzesi factor

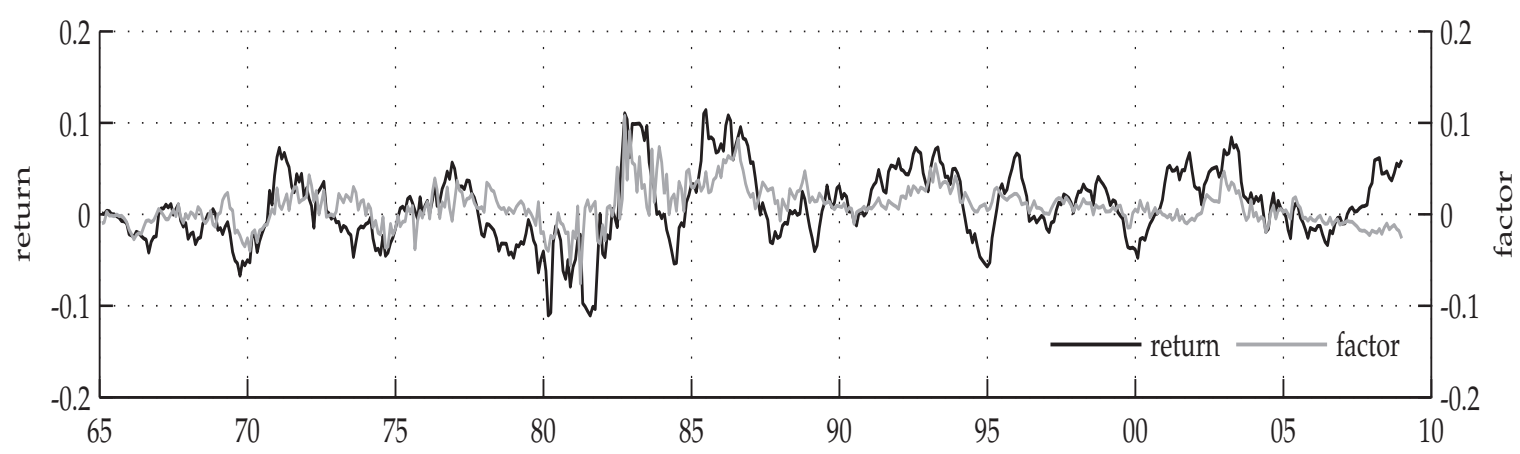

(b) Ludvigson-Ng factor

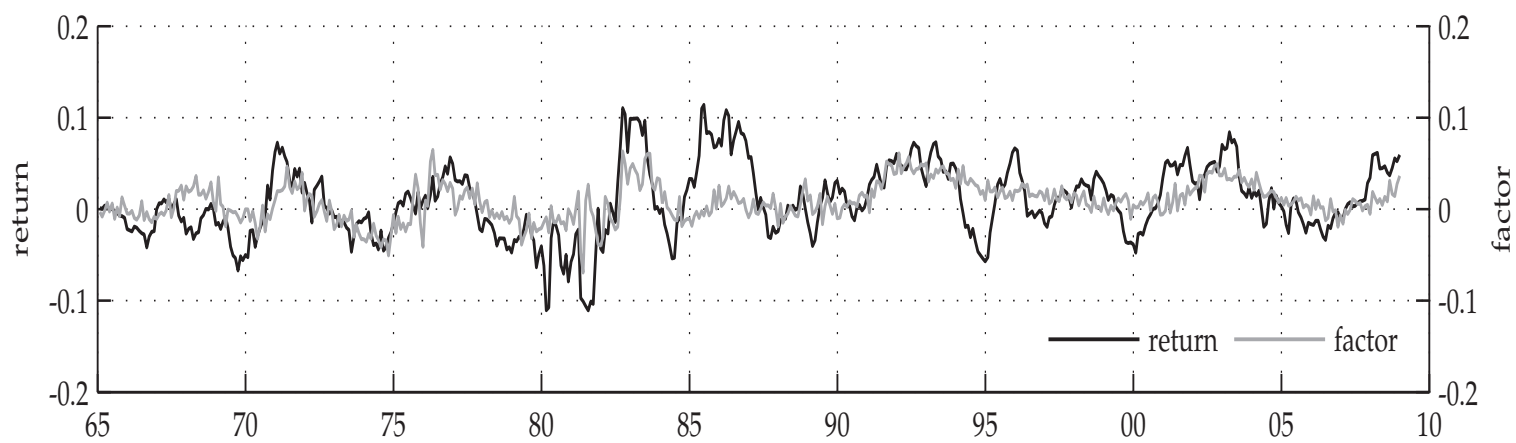

(c) $D_{12} I L R$ liquidity factor

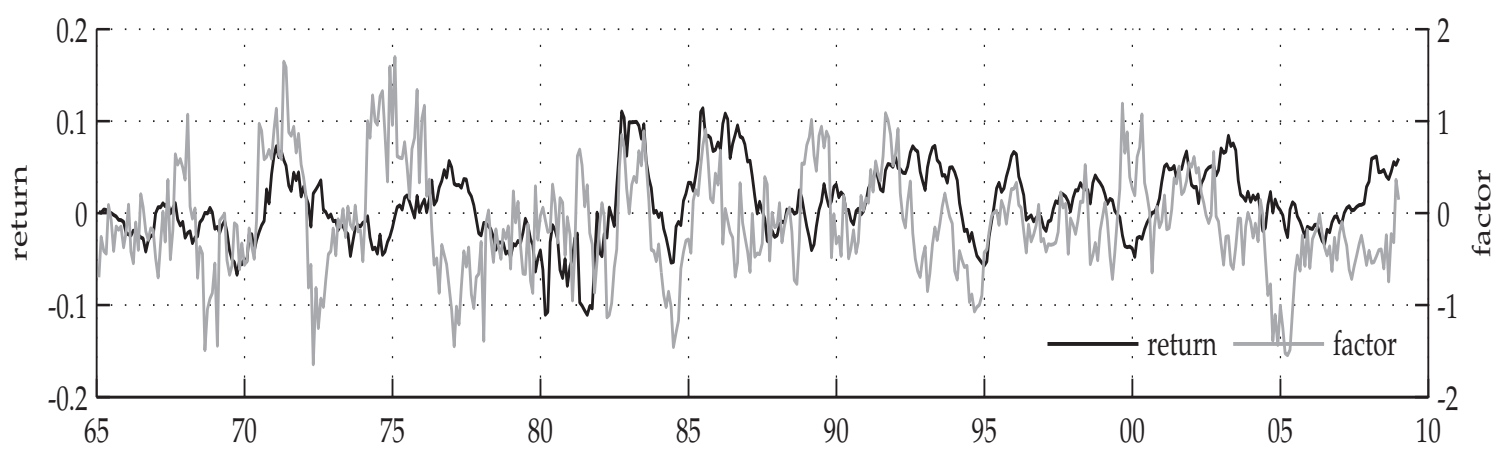

(d) $D_{12} I L R S M B$ liquidity factor

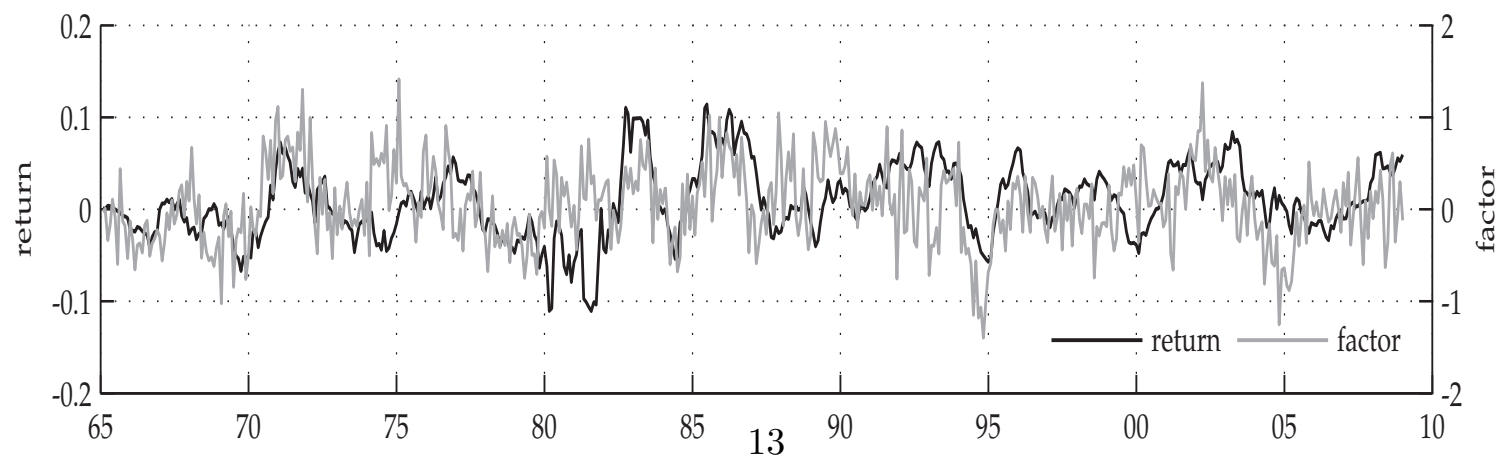




\section{Results}

\section{A In-sample Predictions}

Table II presents the results on the regression of the equally weighted bond premia on stock market illiquidity. For each regression, we report heteroskedasticity and serial-correlation robust p-values, bootstrapped p-values, the $R^{2}$, and the adjusted $R^{2}$. We use the Newey-West corrected standard errors for serial correlation with 18 lags following Cochrane and Piazzesi (2005). Both stock market illiquidity measures have a positive impact on excess bond returns, i.e., increasing illiquidity in the equity market leads to higher excess bond returns one year ahead. The impact of $D_{12} I L R S M B$ is much stronger than $D_{12} I L R$. $D_{12} I L R S M B$ explains $7 \%$ of the variation of yearly excess returns, while $D_{12} I L R$ explains $2 \%$ of the variation. When $D_{12} I L R S M B$ is large, investors may pull out of the smallest and least liquid stocks, causing the gap between the two to increase before recessions.

The explanatory power of the illiquidity variables alone is much smaller than that of the nine macro factors of Ludvigson and $\mathrm{Ng}$ and the forward rates of Cochrane and Piazzesi, which combined, explain $41 \%$ of the monthly variation in future bond excess returns. Nonetheless, stock market illiquidity variables add to the explanatory power of the previously used factors. When adding $D_{12} I L R$ to the macro factors and forward rates, the explanatory power increases by $1 \%$. When adding $D_{12} I L R S M B$, the explanatory power increases by $4 \%$. Both coefficients are highly statistically and economically significant. We find that one standard deviation change in $D_{12} I L R S M B$ increases expected excess returns by about 45 basis points.

In columns (14) and (16) of Table II, we report regressions using the Ludvigson-Ng (LN) factor and Cochrane-Piazzesi (CP) factor, the linear combinations of the nine macro factors and the forward rates respectively. The results remain quantitatively similar when we apply these changes. We use the $L N$ and $C P$ factors for the rest of the analysis, because it provides a more compact representation of the results. The estimated coefficients for the liquidity variables are stable and always two standard deviations away from zero, as shown in Figure 2. The bootstrapped p-values do not lead to changes in our conclusions.

Table III reports results from the in-sample forecasting regression for two-, three-, four-, and five-year log excess bond returns. Here, we ask if stock market illiquidity has predictive power for excess bond returns for individual maturities conditional on previously used factors. As a 


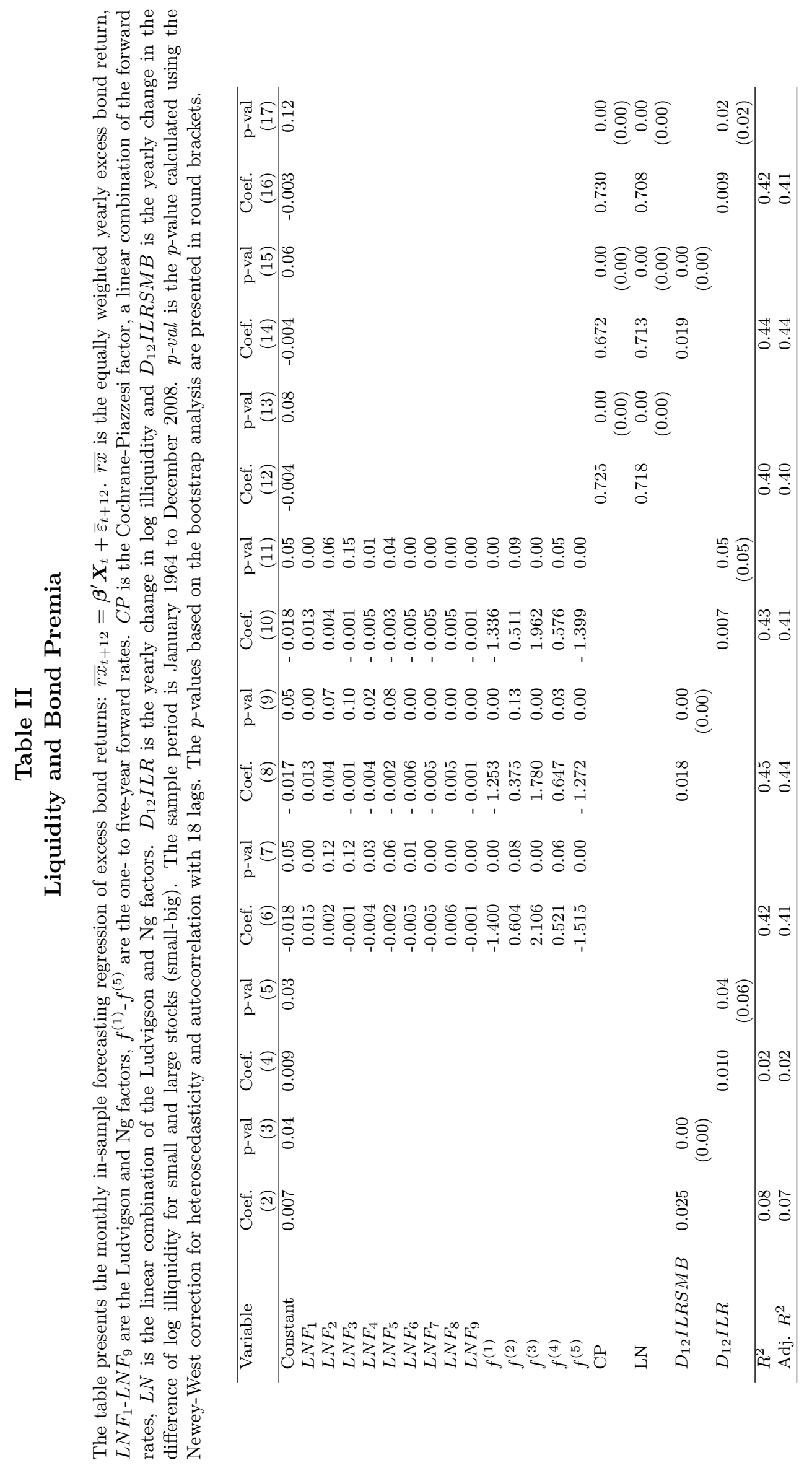




\section{Figure 2}

\section{Parameter Stability of Illiquidity Variables}

The figure presents the recursive estimates of the liquidity coefficients in the in-sample forecasting regressions in columns (14) and (16), in Table II, in Panels A and B respectively. The dotted lines show the 95\% confidence intervals.

(a) $D_{12} I L R$

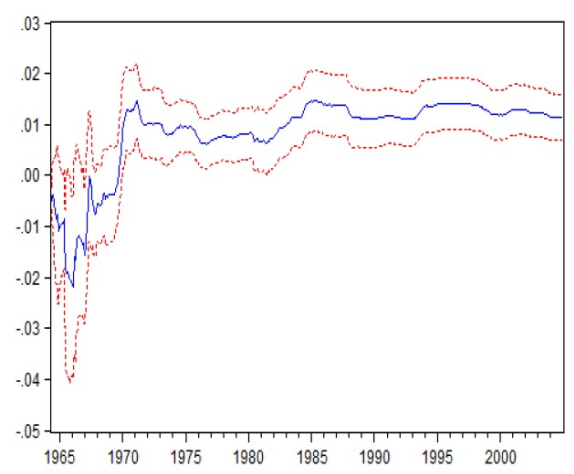

(b) $D_{12} I L R S M B$

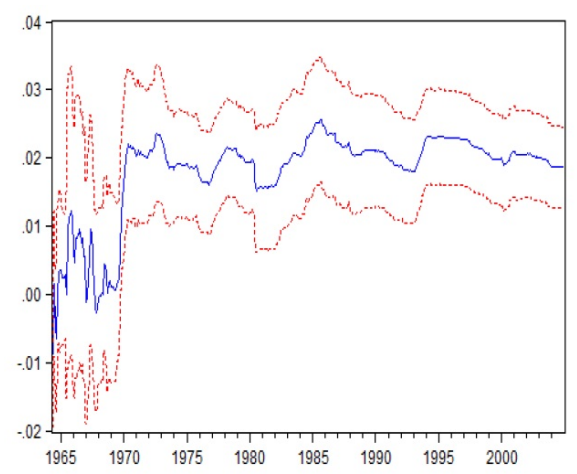

benchmark, we report the regression specification that includes only the $L N$ and $C P$ factors. The results show that these factors are highly statistically significant, at the $5 \%$ level, and the adjusted $R^{2}$ for next year's two-, three-, four-, and five-year log excess bond returns are $38 \%$, $39 \%, 41 \%$, and $38 \%$ respectively. Our results are extremely close to those reported in Table 2 of Ludvigson and $\mathrm{Ng}(2009){ }^{8}$ More importantly, the stock market illiquidity variables are still statistically and economically significant with the inclusion of $L N$ and $C P$ factors across all maturities. The adjusted $R^{2}$ s with $D_{12} I L R S M B$, increase to $44 \%, 44 \%, 45 \%$, and $42 \%$ for two-, three-, four-, and five-year log excess bond returns, respectively. The encouraging 3-6\% increase in $R^{2}$ with a single return forecasting factor for all maturities suggests that stock market illiquidity variables contain additional information not encompassed in the $L N$ and $C P$ factors. We also notice that the estimated coefficients for illiquidity monotonically increase with bond maturity. The estimated coefficient for the five-year log excess bond returns regression is 0.024, more than twice the magnitude of the estimated coefficient for the two-year note. The bootstrapped p-values do not lead to changes in our conclusions.

\footnotetext{
${ }^{8}$ This alleviates any potential concerns about the use of the combined factors $L N$ and $C P$ and the longer sample.
} 


\section{B Out-of-Sample Prediction}

Table IV presents the forecasting results for the equally-weighted portfolio and for the two-, three-, four- and five-year excess bond returns. We present the RMSE, the RMSE ratio, the Clark and West (2007) and the Giacomini and White (2006) test statistics, and their $p$-values. The benchmark model only includes the LN and CP factors. The forecasting models that include the stock illiquidity factors $D_{12} I L R$ and $D_{12} I L R S M B$ exhibit lower RMSEs than the benchmark model, i.e., RMSE Ratios less than 1 . The model with $D_{12} I L R S M B$ performs the best. The stock market illiquidity variables appear to add the most to the forecasting power for bonds with shorter maturities, i.e. the two and three-year excess returns. This is in line with the in-sample results, where the liquidity variables lead to larger increases in $R^{2}$ for bonds with shorter maturities.

The difference in out-of-sample forecasting power between the models with the illiquidity variables and the benchmark model with the CP and LN factors is statistically significant. The Clark and West (2007) test shows that the model with stock market illiquidity has superior predictive ability compared to the benchmark model. The $D_{12} I L R S M B$ factor appears to have stronger predictive power than $D_{12} I L R$. These results are confirmed by the stricter Giacomini and White (2006) test results. We regard this result as very good, since the $C P$ and $L N$ factors are very strong and encompass a very large variety of information, thus are quite hard to beat out-of-sample. Consistent with Næs et al. (2011) and Amihud (2002), we find that the difference in liquidity between small and large stocks is more informative both in the in- and out-of-sample analysis. Thus, we use mainly $D_{12} I L R S M B$ for the rest of our analysis and exhibit results for both measures where space permits.

\section{Yield Curve Analysis}

The focus on bond risk premia only provides a partial perspective on the behavior of the yield curve. In this section we take a more comprehensive perspective on the yield curve and investigate how aggregate stock market illiquidity affects the yield curve. We follow Cochrane and Piazzesi (2005) and construct a simple arbitrage-free yield curve model that reproduces the basic annual bond return regressions.

We model the yearly dynamics of the joint vector $\boldsymbol{x}_{t}=\left(y_{t}^{(1)}, f_{t}^{(2)}, f_{t}^{(3)}, f_{t}^{(4)}, f_{t}^{(5)}, L N_{t}, D_{12} I L R S M B_{t}\right)^{\prime}$ 


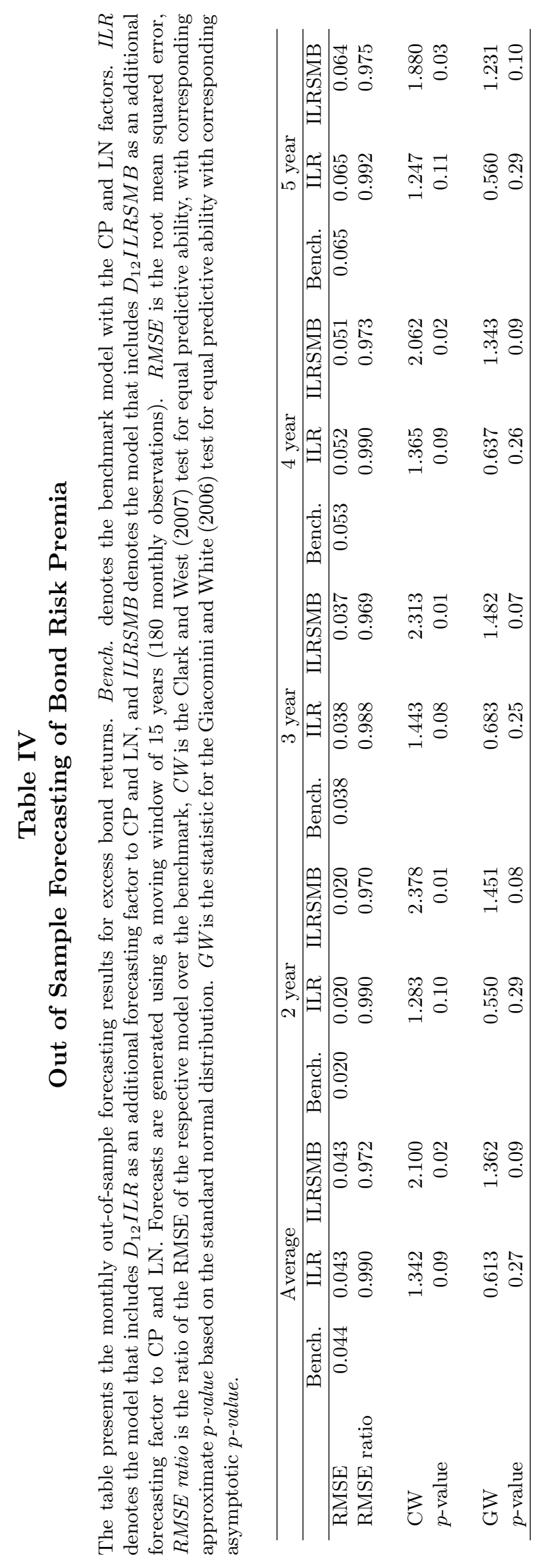


of forward rates, the LN factor, and stock market illiquidity by a first-order VAR model:

$$
\boldsymbol{x}_{t+1}=\boldsymbol{a}_{x}+\boldsymbol{B}_{x} \boldsymbol{x}_{t}+\boldsymbol{\nu}_{x, t+1}, \quad \text { where } \boldsymbol{\nu}_{x, t} \sim \operatorname{IIDN}\left(\mathbf{0}, \boldsymbol{\Sigma}_{x}\right) .
$$

The log excess bond return on a $n$-year zero-coupon bond is given by:

$$
r x_{t+1}^{(n)}=-\sum_{i=1}^{n-1} f_{t+1}^{(i)}+\sum_{i=2}^{n} f_{t}^{(i)}
$$

and is a linear function of forward rates and lagged forward rates. Hence, we apply a nonsingular linear transformation to the VAR model in equation (4) to obtain an equivalent system of regression equations expressed in terms of excess bond returns:

$$
\boldsymbol{z}_{t+1}=\boldsymbol{a}_{z}+\boldsymbol{B}_{z} \boldsymbol{x}_{t}+\boldsymbol{\nu}_{z, t+1}, \quad \text { where } \boldsymbol{\nu}_{z, t} \sim \operatorname{IIDN}\left(\mathbf{0}, \boldsymbol{\Sigma}_{z}\right)
$$

where $\boldsymbol{z}_{t}=\left(r x_{t}^{(2)}, r x_{t}^{(3)}, r x_{t}^{(4)}, r x_{t}^{(5)}, f_{t}^{(5)}, L N_{t}, D_{12} I L R S M B_{t}\right)^{\prime}$. The VAR and the system of equations are equivalent with a unique mapping between the parameters $\boldsymbol{a}_{x}, \boldsymbol{B}_{x}, \boldsymbol{\Sigma}_{x}$ and $\boldsymbol{a}_{z}$, $\boldsymbol{B}_{z}, \boldsymbol{\Sigma}_{z}$ as described in Appendix B. The first four regression equations of this system are the bond return regressions, hence the VAR model can exactly reproduce them. The full yield model complements these bond return regressions with a dynamic regression equation for the longest forward rate, the LN factor, and stock market illiquidity.

The VAR model provides a statistical representation of the joint dynamics of the yield curve, the LN factor, and stock market illiquidity. An important question is whether there is an economic model that rationalizes these dynamics. Following Cochrane and Piazzesi (2005), the model is consistent with a discrete-time Gaussian affine asset pricing model with state variables $\boldsymbol{x}_{t}$. We start by directly specifying the nominal stochastic discount factor as:

$$
M_{t+1}=\exp \left\{-y_{t}^{(1)}-\frac{1}{2} \boldsymbol{\lambda}_{t}{ }^{\prime} \boldsymbol{\Sigma}_{\nu} \boldsymbol{\lambda}_{t}-\boldsymbol{\lambda}_{t}{ }^{\prime} \boldsymbol{\nu}_{t+1}\right\}
$$

where the one-period yield $y_{t}^{(1)}$ and the market prices of risk $\boldsymbol{\lambda}_{t}$ are linear in the state variables:

$$
\begin{gathered}
y_{t}^{(1)}=\delta_{0}+\boldsymbol{\delta}_{1}{ }^{\prime} \boldsymbol{x}_{t} \\
\boldsymbol{\lambda}_{t}=\boldsymbol{\lambda}_{0}+\boldsymbol{\Lambda}_{1} \boldsymbol{x}_{t} .
\end{gathered}
$$


Bonds are priced according to:

$$
p_{t}^{(n)}=\log \mathrm{E}_{t}\left(M_{t+1} \cdots M_{t+n}\right)
$$

The objective is to find a specification of the stochastic discount factor that reproduces the yield curve dynamics implied by the VAR model. Since the state vector $\boldsymbol{x}_{t}$ contains forward rates, it is important that the model is self-consistent in that it reproduces these forward rates exactly. Self-consistency imposes conditions on the parameters $\delta_{0}, \boldsymbol{\delta}_{1}, \lambda_{0}, \boldsymbol{\Lambda}_{1}$ of the stochastic discount factor as described in Appendix B. However, the stochastic discount factor is not uniquely defined and in fact multiple different stochastic discount factors are consistent with the VAR model. Fortunately, this indeterminacy does not affect our analysis since we restrict our analysis only to forward rates contained in $\boldsymbol{x}_{t}$, which are exactly reproduced by all consistent stochastic discount factors.

\section{Results}

The VAR model is estimated equation by equation using OLS. The model describes yearly dynamics, which are estimated from monthly data with overlapping observations, using NeweyWest standard errors. Table V shows the estimation results of the VAR model in equation (4) and the implied estimates for the bond return regressions in equation (5). The implied estimates of the bond return regression in columns (9)-(12) in Panel A of Table V closely match the bond return regressions in Table III. Differences are mainly due to directly including individual forward rates instead of the CP factor. Results in Panel B show that innovations in illiquidity exhibit a weak negative correlation with innovations in forward rates.

The VAR can be used to derive impulse response functions to examine the impact of a shock to aggregate stock market illiquidity on the yield curve. The innovations in Equation (4) are correlated and have to be orthogonalized to define meaningful shocks. We orthogonalize the innovations by using a Choleski decomposition of $\boldsymbol{\Sigma}_{\nu}$ based on a causal ordering from the LN factor to aggregate stock market illiquidity to the yield curve. Hence, a shock to aggregate stock market illiquidity is defined as orthogonal to a macro shock to the LN factor. The illiquidity shock can be contemporaneously correlated with the yield curve, which allows the illiquidity variable to explain part of the cross section of forward rates. 


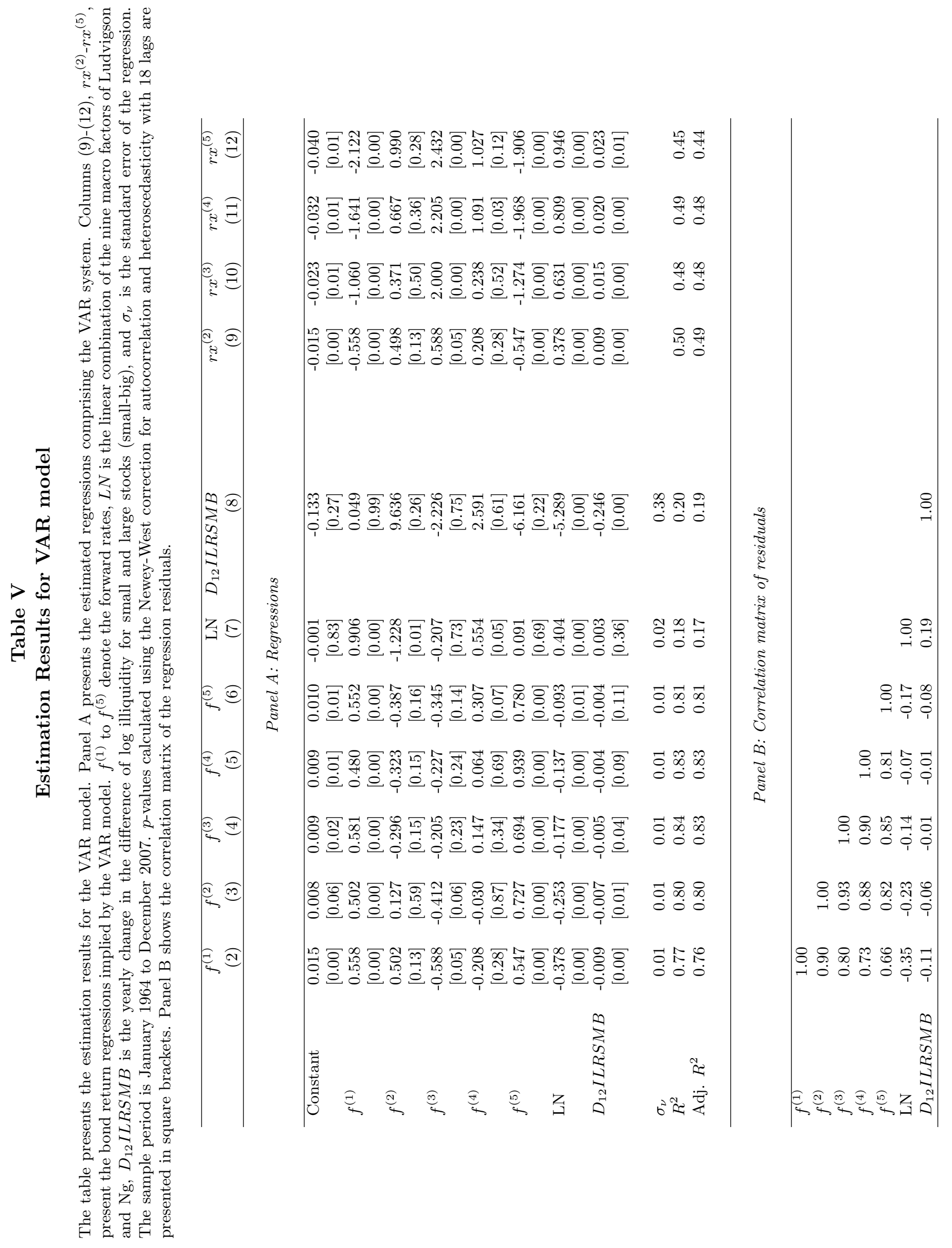




\section{Figure 3}

\section{Impulse Response of Yield Curve}

The figure presents the response of the yield curve to a shock in aggregate stock market illiquidity $D_{12} I L R S M B$.

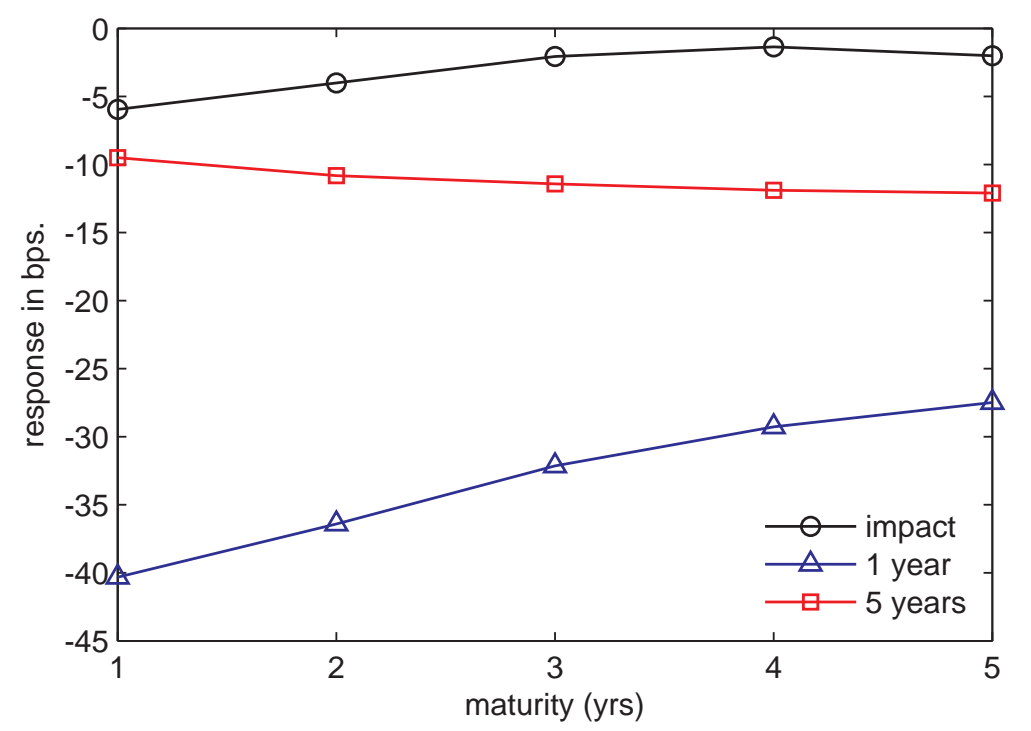

Figure 3 shows the response of the yield curve to a positive one-standard-deviation shock in aggregate stock market illiquidity. The yield curve is contemporaneously not affected by the shock. The one-year yield drops by about 5 basis points and longer rates drop even less. The illiquidity variable only has a marginal effect in explaining the current yield curve and may act as a "hidden factor" to the yield curve (Duffee, 2011). However, the shock has a strong negative effect on the yield curve after one year. The one-year yield declines by over 40 basis points while longer yields drop by more than 25 basis points. This decrease in yields implies an appreciation in bond prices generating a positive excess bond return. For subsequent years the effect gradually dies out.

The yield on a long-term bond equals the average expected short-term yields over the life of the bond plus a risk premium. Hence, we can decompose the yield on a long-term bond in two parts: expectations and risk premium:

$$
y_{t}^{(n)}=\underbrace{\frac{1}{n} E_{t}\left(y_{t}^{(1)}+\ldots+y_{t+n-1}^{(1)}\right)}_{\text {expectations part }}+\underbrace{t p_{t}^{(n)}}_{\text {risk premium }}
$$

The expectations part can be obtained directly from the VAR model and hence the impulse 
Figure 4

Decomposition of Impulse Response Function of 5-Year Yield

The figure presents the impulse response function of the 5 -year yield to a shock in aggregate stock market illiquidity $D_{12} I L R S M B$. The impulse response function of the 5-year yield is decomposed into an expectations part and a risk premium.

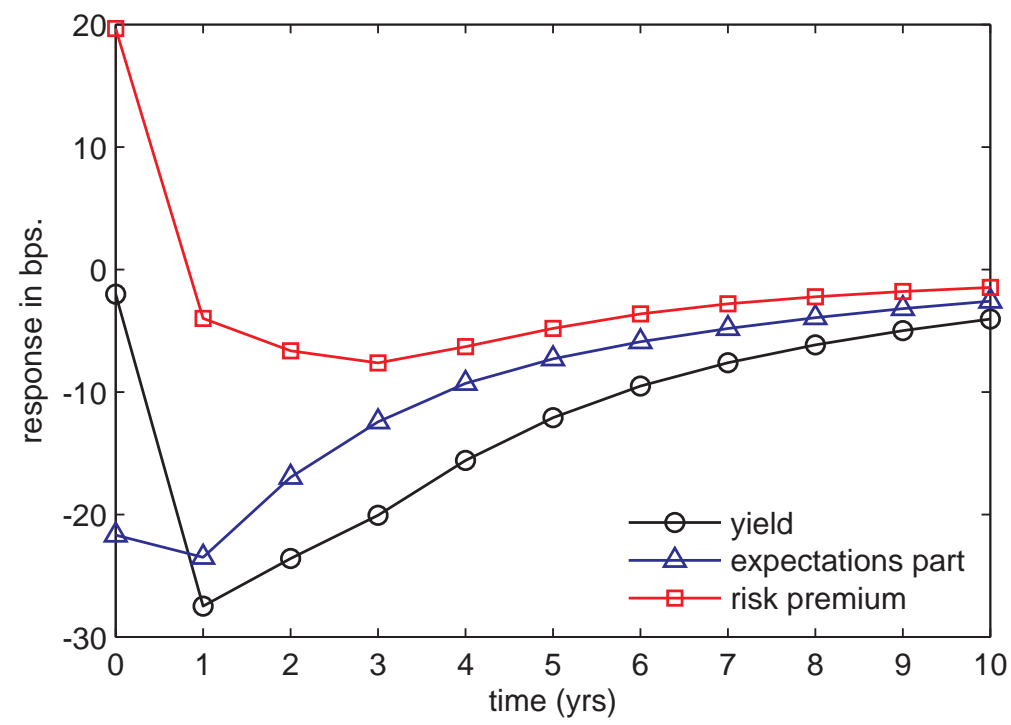

response function for a yield can be decomposed as well. Figure 4 plots the impulse response function to a shock in illiquidity for the five-year yield and its decomposition. As before, the yield is marginally affected contemporaneously by the shock. However, in the decomposition, the expectations part shows a strong negative effect, which is compensated by a strong positive effect on the risk premium. The effect on the risk premium disappears in subsequent periods, while the effect on expectations slowly decays, such that the net effect on the yield is negative.

\section{Robustness}

\section{A Monthly Bond Portfolio Returns}

Ferson, Sarkissian, and Simin (2003) highlight the importance of addressing spurious regression bias in predictive regressions with persistent variables. Because the overlapping scheme we adopt in the bond return regressions in Section IV might induce strong autocorrelation, we investigate the validity and robustness of our results using monthly returns for portfolios of Treasury bills and bonds, following Duffee (2012). We use CRSP bond portfolio returns with maturities up to one year, between one and two years, two and three years, three and four 
years, four and five years, and five and ten years. Excess returns are obtained by subtracting the 1-month T-bill rate from the portfolio returns. While this is different from Cochrane and Piazzesi (2005) and our earlier exercise in studying annual returns, Duffee (2012) argues that predicting monthly excess returns of these bond portfolios provides an alternative test to the statistical significance of predictive variables.

We repeat the analysis in Section IV using monthly bond portfolio returns as the dependent variable. We first run a regression of the monthly equally-weighted bond portfolio returns on the nine macro factors of Ludvigson and $\mathrm{Ng}$ and the forward rates of Cochrane and Piazzesi, presented in Table A1 in the Appendix. These variables explain $14 \%$ of the variation in average portfolio returns. As in previous analysis, we also use the combined CP and LN factors described in Section 2. The combined factors perform poorly compared to the individual factors. This is not surprising because they were constructed using the annual excess bond returns. We reestimate the CP and LN factors using the same methodology as in equations 2 and 3 using the equally-weighted monthly bond portfolio return as the dependent variable and create two new variables: $C P B P$ and $L N B P$. These two factors explain almost the same amount of variation in the bond portfolio returns as the individual macro factors and forward rates. We use the $C P B P$ and $L N B P$ factors for the remaining in-sample and out-of-sample analysis.

\section{In-sample Prediction}

Table VI presents the results for the regression of the equally-weighted bond portfolio returns equivalent to Table II, i.e. for time $t$ in months:

$$
\bar{r}_{m, t}=\theta_{0}+\boldsymbol{\theta}_{1}^{\prime} \boldsymbol{X}_{t}+\bar{\varepsilon}_{m, t},
$$

where $\overline{r x}_{m}$ is the equally-weighted monthly bond portfolio return. As before, there is a positive relation between the illiquidity variables and bond excess returns. Stock market illiquidity variables are highly statistically significant, and they explain $2 \%$ of the monthly variation in bond portfolio excess returns. Economically, an increase by one standard deviation in $D_{12} I L R S M B$ increases monthly bond excess returns by 12 basis points.

Table VII reports results from the in-sample forecasting regression for bond portfolio returns for all maturities. The statistical significance of the illiquidity variables is high for each of the six individual bond portfolio return regressions. The addition of the stock market illiquidity 


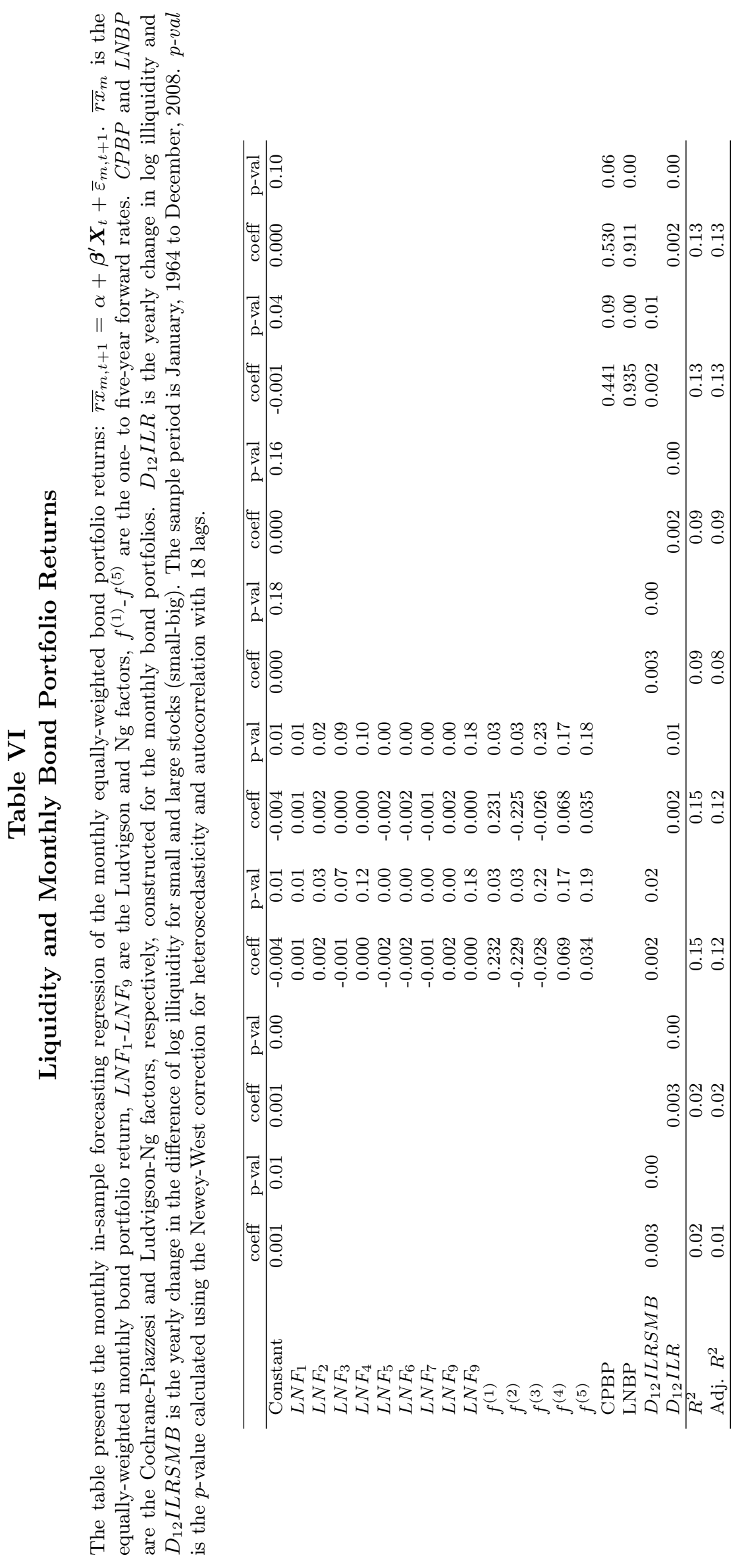


variables to the $C P B P$ and $L N B P$ factors increases the adjusted $R^{2}$ by $1-3 \%$ for all maturities. As noted before with the Fama-Bliss portfolios, the impact of stock market illiquidity increases with the maturity of the bonds and its explanatory power decreases with the maturity of bonds.

\section{Out-of-sample Prediction}

Table VIII presents the out-of-sample forecasting results for the equally weighted bond portfolio and for six individual monthly bond portfolio excess returns. The forecasting models that include the stock market illiquidity factors $D_{12} I L R$ and $D_{12} I L R S M B$ exhibit lower root mean squared errors than the benchmark model, as can be seen from the RMSE ratio. The stock market illiquidity variables appear to add the most to the forecasting power for bonds with shorter maturities, i.e. the $<1$ year to $2-3$ year excess returns. This is in line with the in-sample results, where the liquidity variables lead to larger increases in $R^{2}$ for bonds with shorter maturities, and the out-of-sample results for the annual returns in Section 4.2. The difference in the out-of-sample forecasting power between the models with the liquidity variables and the benchmark model with the CPBP and LNBP factors is statistically significant using both the Clark and West (2007) and the Giacomini and White (2006) tests. Overall, these results reflect the robustness of stock market illiquidity as a predictive variable for excess bond returns.

\section{B Long-run Inflation Expectations and Macroeconomic Disagreement}

Cieslak and Povala (2011) argue the importance of accounting for long-run inflation expectations when considering excess bond return predictability. They decompose yields into long-horizon expected inflation and maturity-related cycles and use the cycles to construct a return forecasting factor similar to Cochrane and Piazzesi (2005). Following their work, we construct the Cieslak-Povala factor. Buraschi and Whelan (2012) show that belief dispersion regarding the real economy, inflation, and yields predict excess bond returns. To investigate if the stock market illiquidity variable is capturing belief dispersion, we construct expectation dispersion measures for one-quarter and one-year ahead expectations for: real GDP (RGDP 1Q, RGDP $1 Y$ ), industrial production growth (INDPROD 1Q, INDPROD 1Y), GDP deflator (GDP Deflator 1Q, GDP Deflator 1Y), CPI (CPI 1Q, CPI 1Y), and the difference in forecasts for the 3-month Treasury bill and 10-year note rates (Tbill-Notes $1 Q$, Tbill-Notes $1 Y$ ). These dispersion measures are collected from the widely-used and publicly available Survey of Professional 


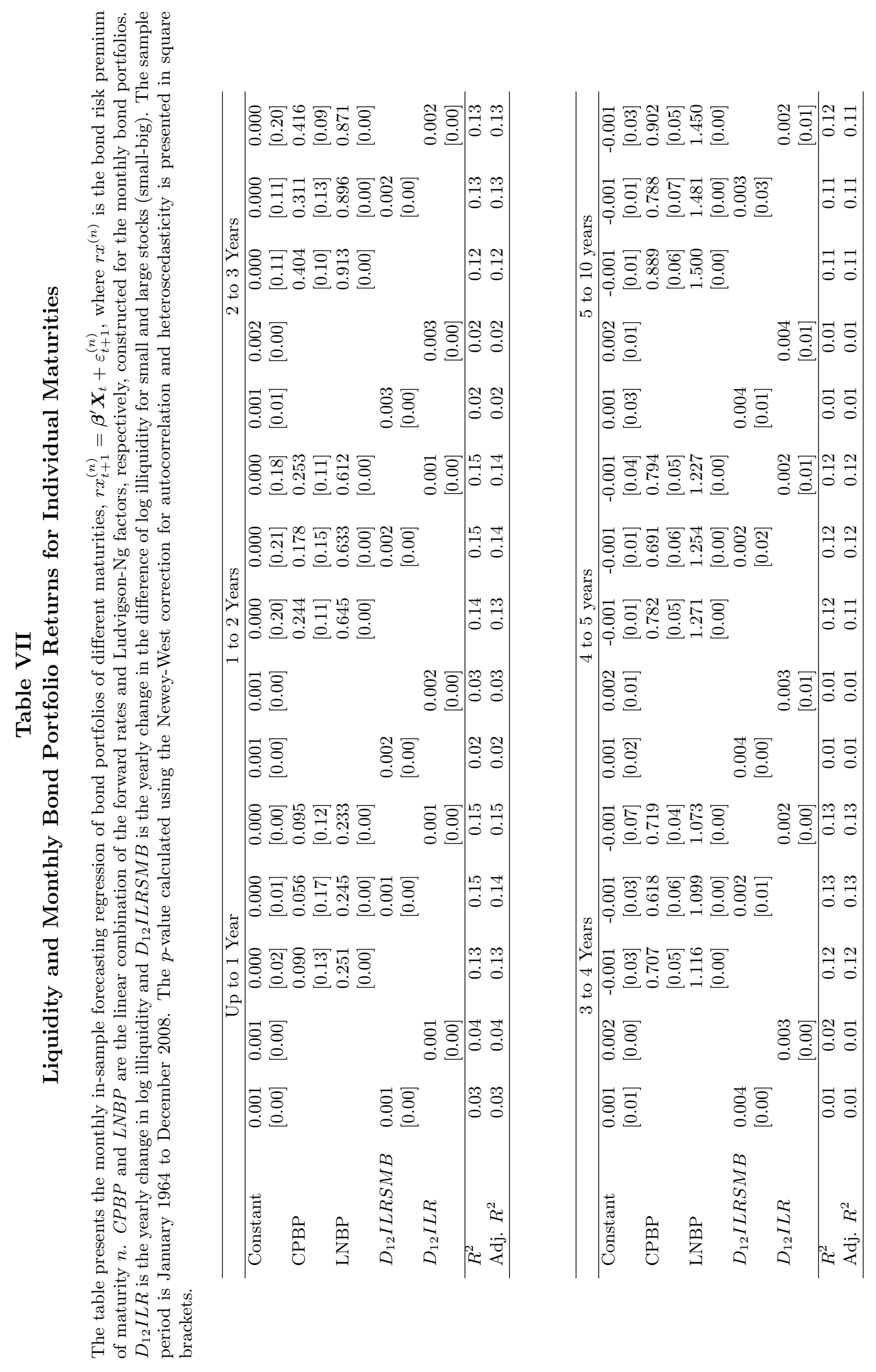


藏密

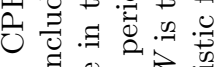

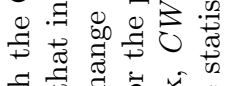

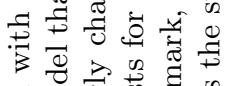

彜

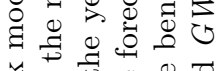

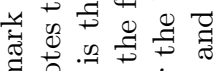

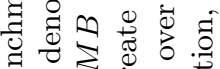

원

的娄

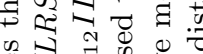

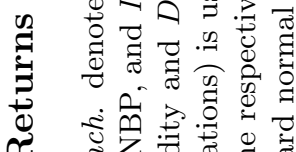

争

皇

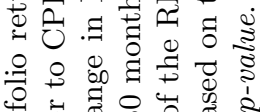

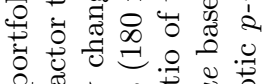

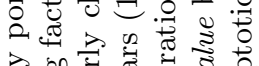

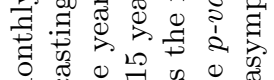

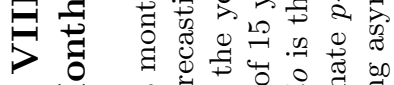

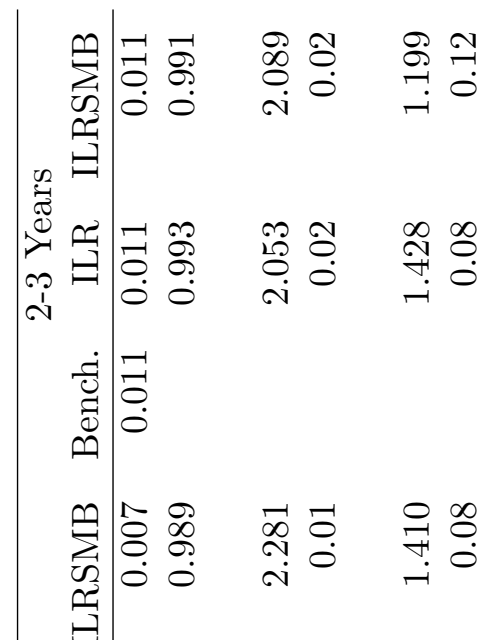

的

ल च

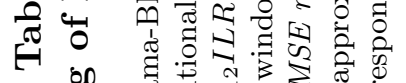

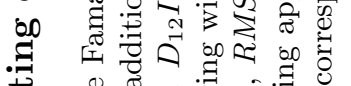

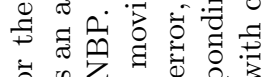

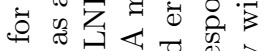

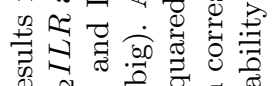

…ㄴ.

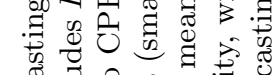

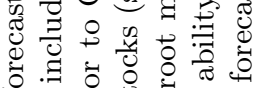

证

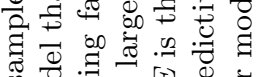

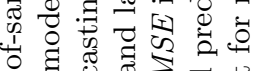

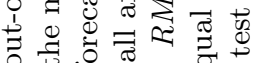

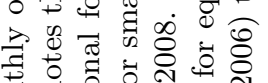

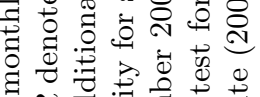

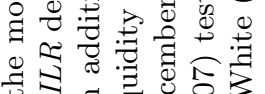

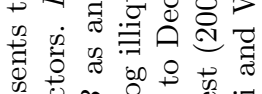

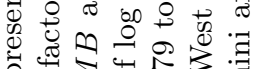

성

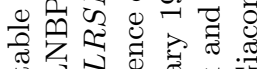

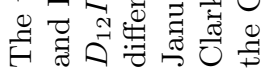

焉

过

$\infty$

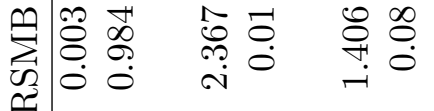

ส

V

:

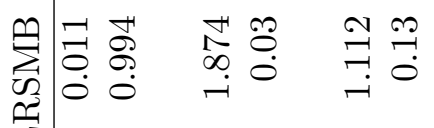

⿶

芫

它

承

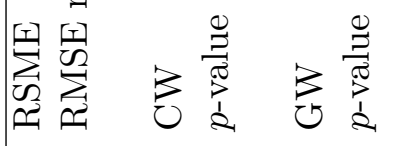

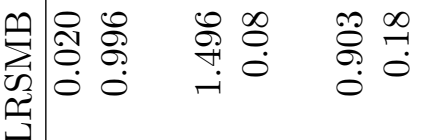

描

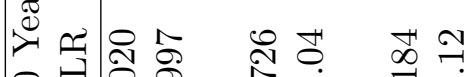

午

렁

๑

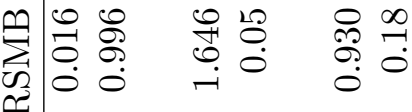

的

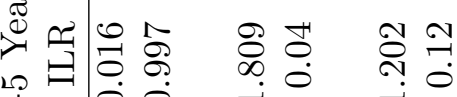

L

通苞

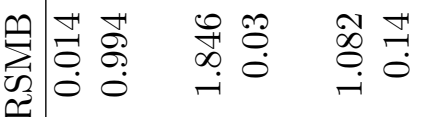

的

范

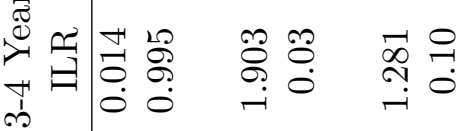

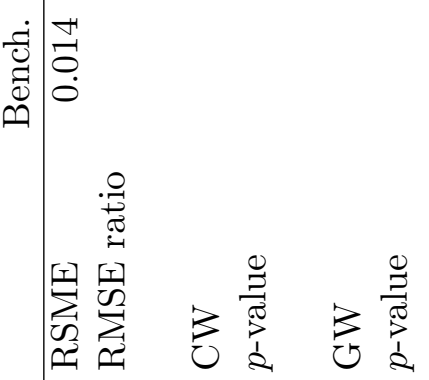


Forecasters (SPF) data provided by the Philadelphia Fed. ${ }^{9}$

We include the dispersion in beliefs variables and the Cieslak-Povala factor in the bond premia regression together with $\mathrm{CP}, \mathrm{LN}$, and $D_{12} I L R S M B$. In Table A2, we show that the illiquidity variable remains highly statistically and economically significant, and it increases the adjusted $R^{2}$ by $4-5 \%$ over other variables. The results suggest that the illiquidity variable is not capturing information about long-run inflation expectations and dispersion in beliefs.

\section{Futures Market}

In a recent paper, Hong and Yogo (2012) show that not only futures prices but also open interest in the futures market are important indicators of future economic activity and can predict equity, bond, and currency returns. In order to understand whether stock market illiquidity is capturing information already in the futures market, we estimate contemporaneous and lagged regressions of illiquidity and futures returns and futures open interest, as in Hong and Yogo (2012). ${ }^{10}$ The results in Table A3 in the Appendix show that stock market illiquidity is not associated either contemporaneously or with a lag to futures market information. In most specifications the model p-value is higher than $10 \%$, suggesting that these are inadequate variables for explaining stock market illiquidity. In further robustness analysis in Panel E, we include the Hong and Yogo (2012) variables in the bond premia regression together with CN, LN, and $D_{12} I L R S M B$. The illiquidity variable remains highly statistically and economically significant.

\section{Why Does Market Liquidity Matter?}

In the introduction, we argue that stock market illiquidity could be related to bond excess returns via bond liquidity, market-wide private information, investment, "flight-to-quality", and funding liquidity. In this section we investigate each of these explanations.

\section{A Bond Market Liquidity}

One important determinant of bond risk premia is the liquidity of the Treasury market itself. Following Fleming (2003), Goyenko and Ukhov (2009), and Goyenko, Subrahmanyam, and

\footnotetext{
${ }^{9}$ The data is available at http://www.philadelphiafed.org/research-and-data/real-time-center/survey-ofprofessional-forecasters/. The SPF survey is conducted quarterly. To obtain monthly data, we linearly interpolate between quarterly observations following Cieslak and Povala (2011) and Kiley (2008).

${ }^{10}$ The data is available from https://sites.google.com/site/motohiroyogo/home/publications.
} 


\section{Table IX \\ Bond Risk Premia and Stock and Bond Iliquidity}

The table presents the monthly in-sample forecasting regression of excess bond returns and stock and bond market illiquidity: $\overline{r x}_{t+12}=\boldsymbol{\beta}^{\prime} \boldsymbol{X}_{t}+\bar{\varepsilon}_{t+12} . \overline{r x}$ is the equally-weighted yearly excess bond return, Bond Illiquidity is the Treasury market illiquidity measured as the log yearly change in the average monthly relative bid-ask spread for 2 to 5 year bonds, $C P$ is the Cochrane Piazzesi factor, $L N$ is the linear combination of the Ludvigson and $\mathrm{Ng}$ factors, $D_{12} I L R$ is the yearly change in log illiquidity, and $D_{12} I L R S M B$ is the yearly change the difference of log illiquidity for small and large stocks (small-big). The sample period is January 1964 to December 2007. p-val is the $p$-value calculated using the Newey-West correction for heteroscedasticity and autocorrelation with 18 lags. All regressions include a constant, not reported to conserve space.

\begin{tabular}{lrrrr}
\hline & \multicolumn{4}{c}{ Average } \\
& Coef. & Prob. & Coef. & Prob. \\
\hline Constant & -0.005 & 0.42 & -0.003 & 0.63 \\
Bond Iliquidity & -0.010 & 0.10 & -0.010 & 0.10 \\
CP & 0.652 & 0.00 & 0.709 & 0.02 \\
LN & 0.741 & 0.00 & 0.736 & 0.00 \\
$D_{12}$ ILRSMB & 0.018 & 0.00 & & \\
$D_{12}$ ILR & & & 0.009 & 0.09 \\
$R^{2}$ & 0.45 & & 0.43 & \\
Adj. $R^{2}$ & 0.45 & & 0.43 & \\
\hline
\end{tabular}

Ukhov (2011), we use the standard measure of liquidity of the treasury market: relative quoted bid-ask spread. The quoted bid and ask prices are from the daily Treasury Quotes file in CRSP from January 1964 to December 2007. The file includes Treasury fixed income securities of 3 and 6 months and 1,2,3,5,7,10,20, and 30 years to maturity. Once issued, the security is considered as on-the-run and the older issues are off-the-run. We use the daily data for onthe-run treasuries to calculate monthly average bid-ask spreads for bonds with two to five year maturity. Then construct the equally-weighted spread from the 2 to 5 year bonds to match the equally-weighted risk premium.

The bond liquidity series exhibits a unit root, therefore we take the yearly log difference in the same way as for the stock market illiquidity. The results in Table IX show that bond market illiquidity is not significant at the conventional $10 \%$ significance level. The statistical and economic significance of stock market illiquidity is not affected by the introduction of bond market illiquidity. ${ }^{11}$

\footnotetext{
${ }^{11}$ Unfortunately, the CRSP Treasury bid-ask spread data is of poor quality for more recent years. For the period after 1994, there is almost no variation in the bid-ask spread of any of these securities. Michael Fleming at the New York Fed has collected information on the bid-ask spread of 3 and 6-month bills from GovPX, an electronic platform where treasuries were heavily traded in the period 1994-2004. We use his measure of bid-ask spreads to amend the liquidity measure from CRSP, by replacing the CRSP Treasury bills bid-ask spreads with the GovPX bid-ask spread for the period August 1994-December 2004. The results remain unchanged.
} 


\section{B Market-wide Private Information}

Albuquerque et al. (2008) build a model where they separate firm specific and market-wide private information and liquidity trades. This leads to a generalized version of the Easley et al. (1996) model, which allows for trading in multiple stocks and for two reasons: firm-specific and market-wide information. They construct market-wide private information (MPI) from the order flow for five industries which have substantial exports and imports: Primary Smelting and Refining of Nonferrous Metal (MPI1), Oil and Gas Field Machinery and Equipment Manufacturing (MPI2), Aircraft Manufacturing (MPI3), Aircraft Engine and Engine Parts Manufacturing (MPI4), and Other Aircraft Parts and Auxiliary Equipment Manufacturing (MPI5). All series start in January 1993, but their ending dates vary. Series MPI1 ends in December 2002, series MPI2 ends in June 2002, the series for MPI3 and MPI4 end in December 1999 and December 2000 respectively, and MPI5 ends in February 2003. The series for MPI3 and MPI4 are too short to estimate the model with Newey-West standard errors with 18 lags, therefore we only analyze MPI1, MPI2, and MPI5.

The results in Table $\mathrm{X}$ show that market-wide private information variables predict future excess bond returns, consistent with the story in Albuquerque et al. (2008). Nonetheless, the addition of this variable does not affect the predictive power of stock market illiquidity. If anything, the magnitude of the impact of stock market illiquidity increases with the addition of the market-wide private information variable. Thus, we conclude that our variables are not capturing market-wide private information.

\section{Illiquidity and Investments}

For the investment channel to be plausible, stock market liquidity should be able to predict real investment growth and should be related to funding liquidity. Our proxy for investment is real private fixed investment, a component of GDP, provided by the Bureau of Economic Analysis, as in Næs et al. (2011). Table XI presents the quarterly regressions of real private fixed investment growth on lags of stock market illiquidity. From the univariate regressions in Panel A, it is noticeable that stock market illiquidity can explain real private fixed investment growth up to four quarters ahead. A decrease in liquidity by $1 \%$ causes a decrease in investment by $0.02 \%$ in the next quarter, which means roughly $\$ 1$ billion for our sample period. The 


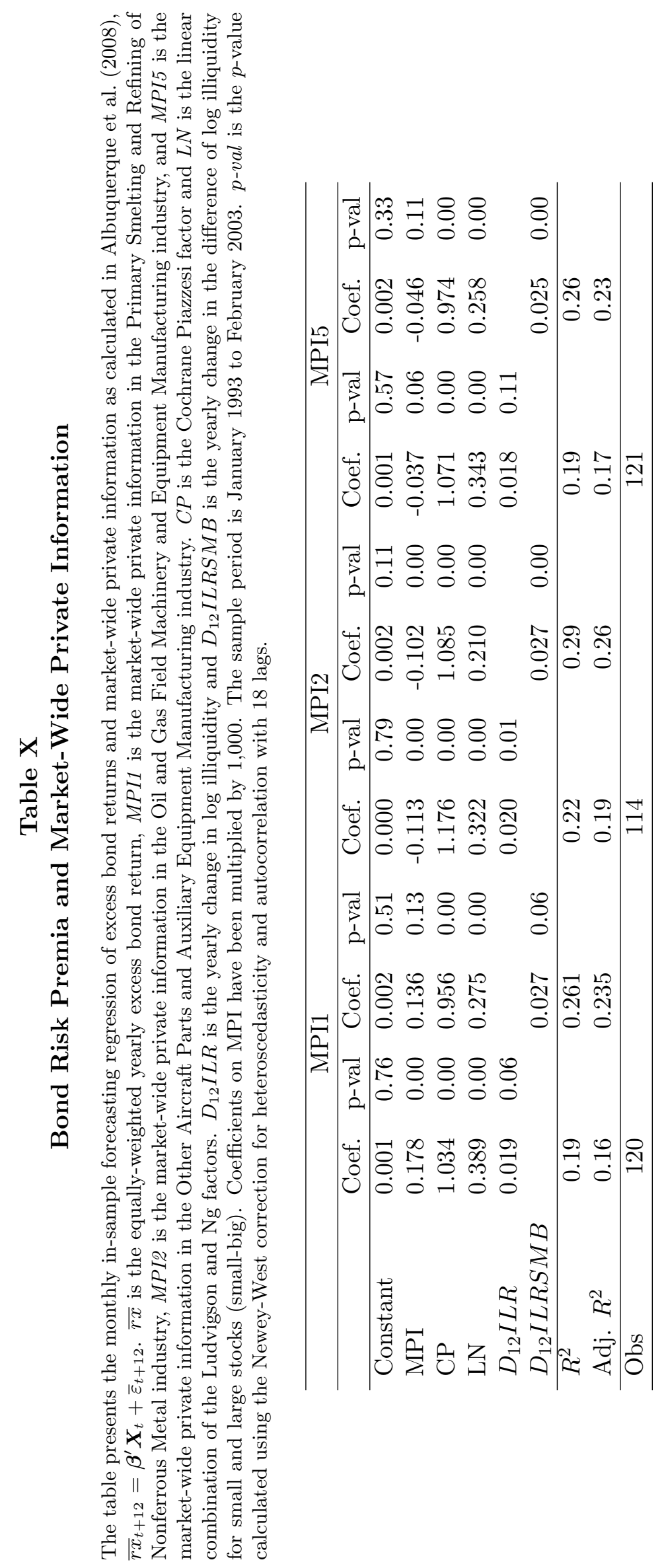


explanatory power of illiquidity is very high in the univariate regressions and even higher in the multivariate regressions, explaining between $16-21 \%$ of the variation in investment growth. Consistent with the investment hypothesis, results from Table XI show that liquidity contains leading information about future investment growth.

Table XI

Investments and Stock Market Illiquidity

The table presents quarterly regressions of real private fixed investment growth and stock market illiquidity. Quarterly data on real private fixed investment is obtained from the Bureau of Economic Analysis. $D_{12} I L R$ is the yearly change in $\log$ illiquidity and $D_{12} I L R S M B$ is the yearly change in the difference of log illiquidity for small and large stocks (small-big). The sample period is Quarter 1 in 1964 to Quarter 4 in 2007. p-val is the $p$-value calculated using the Newey-West correction for heteroscedasticity and autocorrelation. Model p-val is the $p$-value for the model specification F-statistic. All regressions include a constant, not reported to conserve space. Panel A presents the univariate regressions and Panel B presents two multivariate regressions.

Variable Coef. p-val Obs Adj. $R^{2} \quad$ Model p-val

Panel A. Univariate Regressions

\begin{tabular}{llllll}
\hline$D_{12} I L R S M B_{t-1}$ & -0.021 & 0.00 & 175 & 0.15 & 0.00 \\
$D_{12} I L R S M B_{t-2}$ & -0.015 & 0.00 & 174 & 0.08 & 0.00 \\
$D_{12} I L R S M B_{t-3}$ & -0.011 & 0.00 & 173 & 0.03 & 0.01 \\
$D_{12} I L R S M B_{t-4}$ & -0.007 & 0.12 & 172 & 0.01 & 0.10 \\
$D_{12} I L R_{t-1}$ & -0.019 & 0.00 & 175 & 0.19 & 0.00 \\
$D_{12} I L R_{t-2}$ & -0.016 & 0.00 & 174 & 0.14 & 0.00 \\
$D_{12} I L R_{t-3}$ & -0.013 & 0.00 & 173 & 0.09 & 0.00 \\
$D_{12} I L R_{t-4}$ & -0.009 & 0.04 & 172 & 0.04 & 0.01 \\
\hline
\end{tabular}

Panel B. Multivariate Regression

\begin{tabular}{lccccc}
\hline$D_{12} I L R S M B_{t-1}$ & -0.018 & 0.01 & 173 & 0.16 & 0.00 \\
$D_{12} I L R S M B_{t-2}$ & -0.004 & 0.21 & & & \\
$D_{12} I L R S M B_{t-3}$ & -0.003 & 0.38 & & & \\
& & & & & \\
$D_{12} I L R_{t-1}$ & -0.014 & 0.00 & 173 & 0.21 & 0.00 \\
$D_{12} I L R_{t-2}$ & -0.005 & 0.05 & & & \\
$D_{12} I L R_{t-3}$ & -0.004 & 0.09 & & & \\
\hline
\end{tabular}

\section{Stock Market Illiquidity and Flight to Safety}

A potential reason for the relation between stock market illiquidity and bond risk premia could be flight-to-quality via the portfolio shift channel, i.e., investors shift their portfolios towards less risky or safer assets in view of deteriorating future business conditions. Longstaff (2004) shows 
that the flight-to-liquidity premium in Refcorp and U.S. Treasury bonds is related to flight-toquality measured by the inflow into money market mutual funds. Beber et al. (2009) emphasize the importance of flight-to-liquidity and flight-to-quality as avenues to better understand sources of risk premia in sovereign bond markets. Baele et al. (2010) find stock and bond illiquidity factors to be useful in explaining stock and bond return co-movements and suggest that these factors maybe correlated with "flight-to-safety" effects.

\section{Illiquidity and Mutual Fund Flows}

We first investigate the relation between stock market illiquidity and investors' shift in portfolios towards the U.S. sovereign bond market in economic downturns using aggregated net equity and money market mutual fund flows, following Longstaff (2004). Longstaff (2004) argues that money market mutual funds are short-term nearly riskless investments where investors allocate their funds during heightened market uncertainty, because their value is less likely to be affected by market turbulence, while net equity mutual fund flows capture portfolio shifts of confident investors into equity mutual funds during good economic conditions. Consistent with Longstaff (2004), we view the outflow from equity and inflow into money market mutual funds as flightto-quality.

We start with the standard dataset in this literature and use aggregate mutual fund flow data from the Investment Company Institute (ICI) from January 1984 to June 2010. ICI collects monthly sales, asset values, and redemptions by fund for 98 percent of the U.S. mutual fund industry. We construct net flows as (sales-redemptions+(exchange in - exchange out)). Sales and redemptions are actual cash flows that enter or exit a fund family, while "exchanges in" and "exchanges out" are transfers between different funds in the same fund family. The ICI categorizes mutual funds into the following groups: equity, bond, hybrid, and money market funds. Following Warther (1995), we standardize the net flow by lagged total market capitalization to control for time series variation in flow magnitude resulting from price appreciations and market growth. ${ }^{12}$

We start our analysis of flight-to-quality by first examining the correlation structure of fund flows. Panel A of Table A4 in the Appendix shows the correlation of net flows among U.S.

\footnotetext{
${ }^{12}$ Normalizing fund flows with fund assets rather than total market value does not quantitatively change our results. Results can be provided upon reader's request.
} 
mutual funds. There is a positive correlation among the different flows, apart from Taxable money market flows. The largest correlations are between equity and municipal bond flows and hybrid fund flows. This is not surprising, as hybrid portfolios are composed of a mix of stocks and bonds. Money market flows are only positively correlated with Tax exempt money market flows. Bond funds consist of corporate and sovereign bonds, thus using these flows makes it difficult to investigate the flight-to-quality hypothesis, which relates equities and treasury bonds. Money market flows include only funds into short term bonds and are more appropriate to measure flight-to-quality.

Following Chordia et al. (2005), we investigate fund flows correlation during non-crisis and crisis periods. We identify five crisis periods in the sample: Black Monday (October 19, 1987 March 31, 1988), Asian financial crisis (October 1, 1997 - January 31, 1998), Russian Default (July 1, 1998 - December 12, 1988), Dot-com bubble (February 1, 2000 - March 31, 2001), and Credit crisis (July 1, 2007 - present). Panel A of Table A5 shows summary statistics of various fund flows during normal and crisis periods. There is a significant decrease in net flows into equity, hybrid, and bond funds during crises but an increase in net flows to taxable money market funds. This is consistent with suggestions of flight to quality during crisis periods, which causes money to shift from riskier to less risky assets. In addition, Panel A of Table A4 shows that net flows of riskier funds like equity, hybrid, and bond funds become more negatively correlated to money market funds during crises. While the result above is suggestive of the portfolio shift hypothesis of individual investors, the flow variables constructed according to Warther (1995) capture both the actual cash flow entering and exiting a fund family as well as transfers between mutual funds.

In order to study the flows of funds between equity funds and money market funds more carefully, we calculate net exchanges flow variables, (exchange in) - (exchange out), as suggested by Ben-Rephael, Kandel, and Wohl (2012). Thus, we exclude "sales minus redemptions". Net exchange flow captures portfolio shifts among different categories of funds, while net sales and redemptions are likely to be influenced by long-term savings and withdrawals. Figure 5 shows the monthly net exchange equity and money market flows. There is an extremely strong negative relation between them, especially during periods of uncertainty. Panel B of Table A4 shows the correlations among U.S. mutual funds net exchange flows. We observe that net exchange flows into equity mutual funds are positively correlated with net exchange flows to hybrid 


\section{Figure 5}

\section{Equity and Money Market Mutual Fund Flows}

The figure presents the monthly flows into equity and money market mutual funds calculated as net exchange flows. The sample period is January 1984 to January 2010.

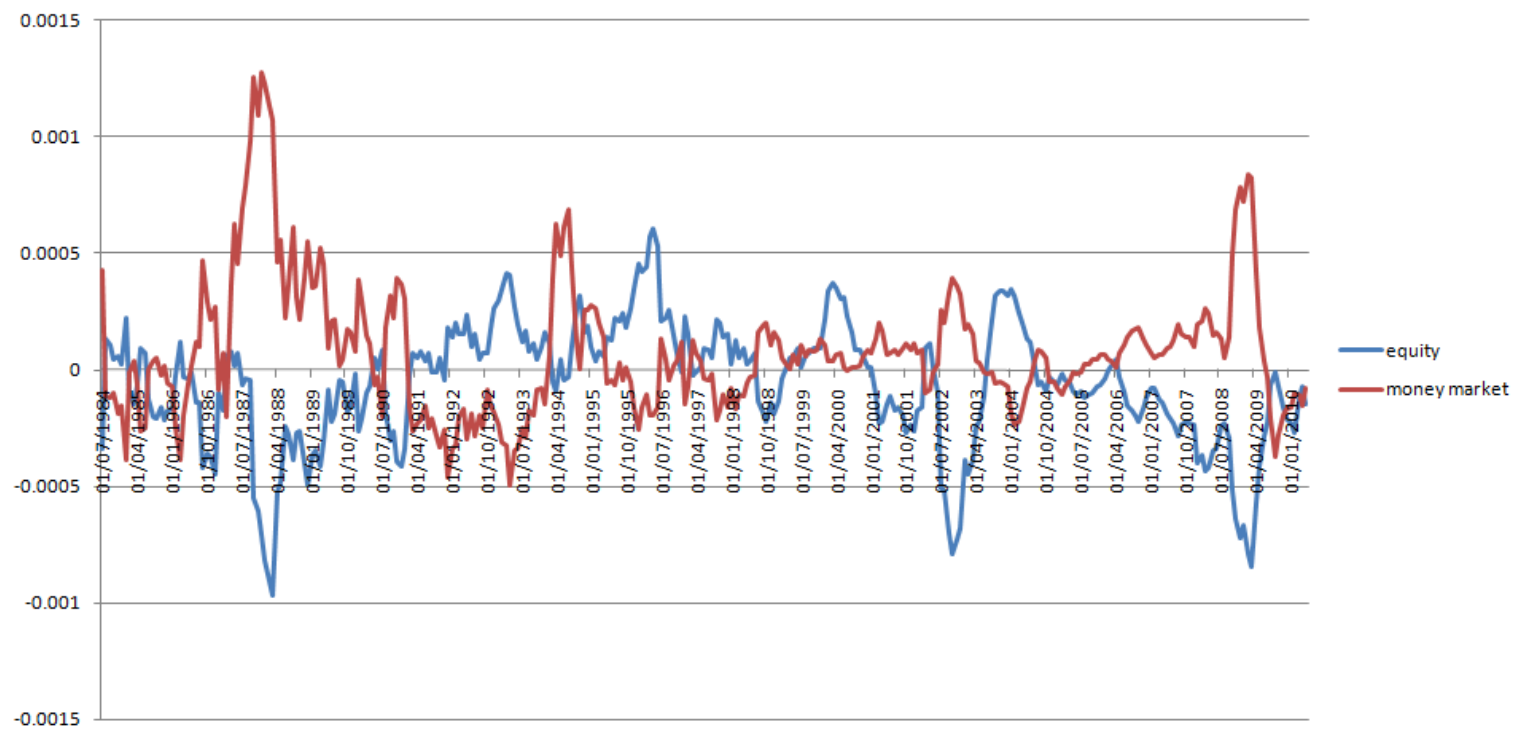

and municipal bond funds as before, even though the correlations are slightly smaller. More interestingly, we observe a highly negative correlation between equity and money market net exchange flows. The negative correlation, -0.83 , is even higher during crisis periods, -0.89 .

Panel A of Table XII shows the correlations between mutual fund net exchange flows and stock market illiquidity, both monthly and yearly changes. Stock market illiquidity is positively correlated up to $30 \%$ with flows into money market funds, i.e., an increase in illiquidity in the stock market is related to increased funds flowing into the safer assets. Stock market illiquidity has a strong negative correlation with flows into equity funds.

\section{Illiquidity and Balanced Mutual Fund Holdings}

An alternative way to investigate the relation between market liquidity and flight to safety is to investigate the behavior of balanced (hybrid) mutual funds. Balanced mutual funds invest both in equity and bonds. Thus, one could proxy the flight-to-quality behavior of managers by looking at the change in the equity holdings relative to bond holdings in balanced funds. We use the CRSP Mutual Fund Database to calculate the end-of-year proportional holdings of equity by balanced funds as the ratio of the total value of their equity portfolio and the net asset value of the fund for the period 1964 to 2007. If asset managers perceive equities as more 


\section{Table XII \\ Stock Market Illiquidity and Flight-to-quality Measures}

The table presents the relation between stock market illiquidity and flight-to-quality measures. $D_{12} I L R S M B$ is the yearly change in the difference of log illiquidity for small and large stocks (small-big). $p$-val is the $p$-value calculated using the Newey-West correction for heteroscedasticity and autocorrelation. All regressions include a constant, not reported to conserve space. Panel A presents the monthly correlation between net exchange mutual fund flows and illiquidity over the period January 1984 to June 2010. DILRSMB is the monthly log change in the difference for small-large stock illiquidity. Panel B presents the yearly regression of equity ratio in balanced funds and stock market illiquidity. The equity ratio for balanced funds is calculated as the ratio of the total value of the equity portfolio and the net asset value of the fund. The sample period is 1964 to 2007. Panel C presents the monthly regressions of the S\&P100 volatility index (VXO) and stock market illiquidity. The sample period is January 1986 to December 2007, 269 observations.

Panel A. Correlations with Mutual Fund Flows

\begin{tabular}{lrrrr}
\hline \multirow{2}{*}{ Variable } & \multicolumn{2}{c}{ Taxable Money } & \multicolumn{2}{c}{ Equity } \\
\cline { 2 - 5 } & Coef. & p-valket & Coef. & p-val \\
\hline DILRSMB & 0.18 & 0.00 & -0.21 & 0.00 \\
$D_{12} I L R S M B$ & 0.18 & 0.00 & -0.24 & 0.00 \\
\hline
\end{tabular}

Panel B. Balanced Funds

\begin{tabular}{lrrrr}
\hline Variable & Coef. & p-val & Coef. & p-val \\
\hline$D_{12} I L R S M B$ & -0.028 & 0.01 & & \\
$D_{12} I L R S M B_{t-1}$ & -0.035 & 0.00 & -0.020 & 0.05 \\
$D_{12} I L R S M B_{t-2}$ & -0.025 & 0.08 & & \\
\hline$R^{2}$ & 0.22 & & 0.05 & \\
Adj. $R^{2}$ & 0.16 & & 0.03 & \\
\hline
\end{tabular}

Panel C. Volatility Index

\begin{tabular}{lrrr}
\hline Variable & Coef. & p-val & Adj. $R^{2}$ \\
\hline$D_{12} I L R S M B_{t-1}$ & 3.64 & 0.00 & 0.04 \\
$D_{12} I L R S M B_{t-2}$ & 3.15 & 0.01 & 0.03 \\
\hline
\end{tabular}

risky than bonds, then they will tend to shift funds from equities towards bonds in periods of economic uncertainty. The results in Panel B of Table XII show that when illiquidity increases, managers of balanced funds shift their portfolios out of equities and into bonds. A $1 \%$ increase in illiquidity leads to a $3 \%$ decrease in stock market exposure.

\section{Illiquidity and S\&P Volatility Index}

To ensure that our results on the relation between illiquidity and flight to safety is robust to other measures of flight to quality, we investigate the relation between illiquidity and the S\&P100 volatility index, VXO. We use VXO instead of the more popular VIX because it is available for 
a longer period, from 1986 instead of 1990. The use of stock index volatility as a proxy for flight to quality is motivated by Bailey and Stulz (1989), where they show an association between stock index volatility and flight to quality. The data is obtained from CBOE Indexes in WRDS. The results in Panel C of Table XII show predictive power of stock market illiquidity for the volatility index, using univariate regressions with one and two lags. Stock market illiquidity is highly statistically significant. An increase in illiquidity by $1 \%$ leads to an increase of 3 points in VXO.

\section{E Market Liquidity, Funding Liquidity, and Flight to Quality}

The flight-to-quality and funding liquidity channels are not mutually exclusive. Thus we study these channels jointly by including mutual fund flows, VXO, and funding liquidity variables into the equally-weighted yearly excess bond return forecasting equation. We use the funding liquidity measure from Fontaine and Garcia (2012), which is constructed from a cross-section of bonds by adding a liquidity factor correlated with bond age to an arbitrage-free term structure model. Table XIII presents the results. In Column (1) of Table XIII, the funding liquidity coefficient is negative and statistically significant. Consistent with the sign found in Fontaine and Garcia (2012), we find that risk premia in Treasury securities decrease when funding liquidity increases. The estimated coefficient of the stock market illiquidity variable remains positive and statistically significant. The magnitude of the estimated coefficient remains very close to that reported in Table II. To investigate the interacting relation between market and funding liquidity in Kiyotaki and Moore (2008) and Brunnermeier and Pedersen (2009), we include an interaction term of the market illiquidity and funding liquidity variables. Column (3) of Table XIII shows that the interaction term is negative and statistically significant. The finding supports Brunnermeier and Pedersen (2009) and Kiyotaki and Moore (2008)'s suggestions of a relation between binding credit (funding) and resaleability (market liquidity) constraints in the market.

We study the role of flight-to-quality on bond risk premia using the net exchange mutual fund flow data. Column (5) of Table XIII presents the estimated coefficients of equity, taxable money market, and taxable bond mutual fund flows. Consistent with a flight-to-quality effect, we find positive and statistically significant coefficients for the taxable money market and bond flows. We find that bond risk premia increase when flows into money market and bond mutual 


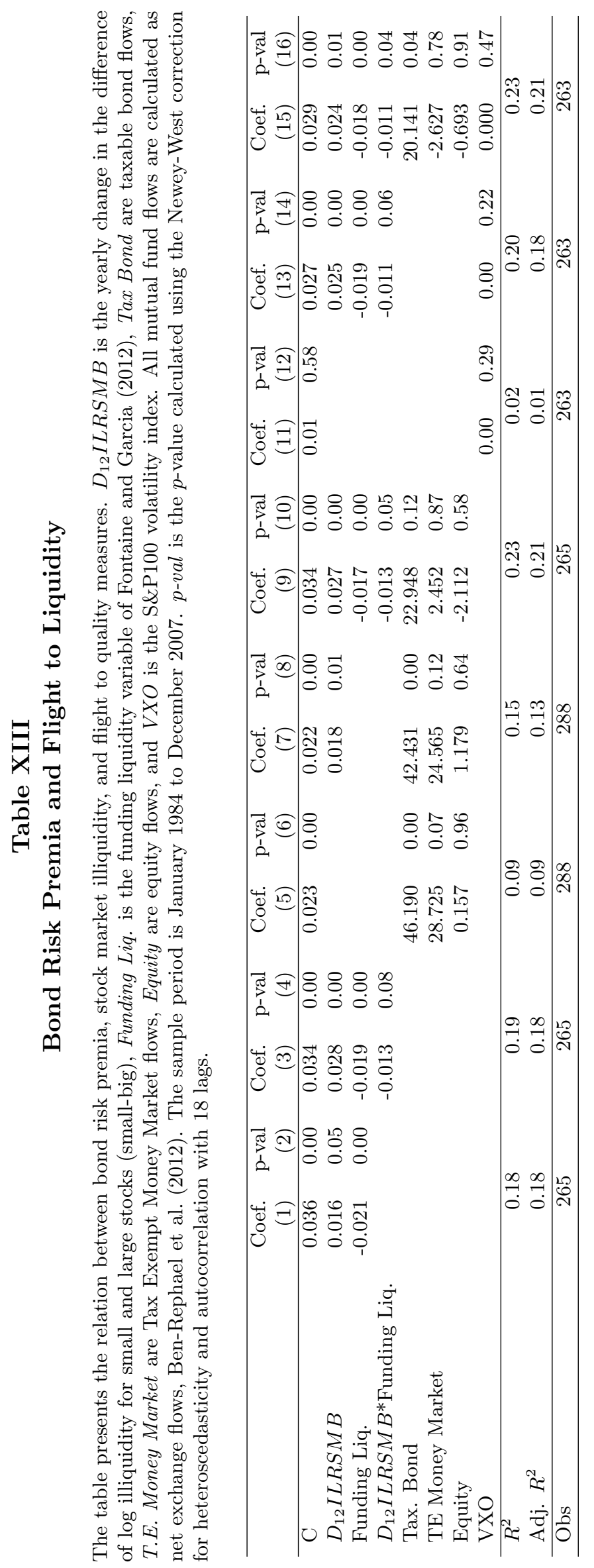


funds increase. Results in column (7) show that stock market illiquidity is related to flight-toquality as we observe that the inclusion of stock market illiquidity subsumed the effect of money market flows. Column (9) shows that the inclusion of market illiquidity, funding liquidity, and their interaction term completely subsume all mutual fund flows variables. The result is robust to the inclusion of VXO, an alternative proxy for flight to quality in columns (13) and (15). ${ }^{13}$ These results are very important because they show the role of funding and market liquidity and their interaction on bond risk premia. While the finding supports the flight to quality and funding liquidity channel, stock market illiquidity appears to contain information beyond these two channels, because it remains significant after controlling for VXO, mutual fund flows, and funding liquidity. This result might come from the timely availability of the market illiquidity variable relative to other bond excess return predictors.

\section{Conclusions}

We assess the effect of stock market illiquidity on U.S. excess bond returns. We use the Amihud (2002) illiquidity measure, the average illiquidity ratio across all stocks, to examine whether excess bond returns can be predicted by stock market liquidity. We find that stock market liquidity adds to the well-established Cochrane-Piazzesi and Ludvigson-Ng factors both in in-sample and out-of-sample forecasting performance. Stock illiquidity has strong forecasting power for excess returns across bonds of all maturities. The effects are statistically and economically significant and stronger for shorter maturity than for longer maturity bonds. Our results are robust to using monthly bond portfolio returns.

We investigate four potential reasons why stock illiquidity contains information about bond excess returns. First, we study whether bond market liquidity can account for this effect. Second, we investigate whether stock market illiquidity contains market-wide private information motivated by Albuquerque et al. (2008). Using market-wide private information data provided by Albuquerque et al. (2008), we find that it is unlikely that stock market liquidity contains market-wide private information. Third, we investigate the flight-to-quality channel of the relation between stock market illiquidity and bond risk premia. We find that changes in illiquidity are related to shifts of U.S. mutual fund flows from equity to money market funds, indicating

\footnotetext{
${ }^{13}$ Results for individual maturity produce qualitatively similar results. See Table A6 in the Appendix.
} 
its relation to flight to quality. In an alternative exercise, we find that stock market illiquidity explains and predicts changes in the average proportion holding of equity and bonds by balanced funds. We also explore the relation between stock market illiquidity and VXO and find that stock market illiquidity is contemporaneously associated and can predict changes to the volatility index.

Finally, we study the funding illiquidity channel. As the flight to quality and funding liquidity channel are not mutually exclusive, we study these channels jointly by including flight to quality variables, like mutual fund flows, VXO, and funding liquidity variables (see Fontaine and Garcia, 2012) into the bond excess return forecasting equations. We find that the inclusion of stock market illiquidity, funding liquidity, and an interaction term of the two subsume all flight to quality variables. The findings provide empirical evidence that supports the theoretical relation between funding and market illiquidity as well as their impact on asset risk premia. Our results suggest that stock market illiquidity is a more timely predictive variable relative to other bond risk premia predictors, and it contains additional information beyond the flight-to-quality and funding liquidity channels. 


\section{Appendix}

\section{A Bootstrap Procedure}

We use a bootstrap procedure to conduct small sample inference on the stock market illiquidity variables in the bond return regressions. In particular, we test the significance of variables of interest in the regression:

$$
y_{t}=\alpha_{0}+\boldsymbol{\alpha}_{1}^{\prime} \boldsymbol{X}_{t}+\eta_{t}
$$

by constructing bootstrap samples of $\left(y_{t}^{*}, \boldsymbol{X}_{t}^{*}\right)$ generated under the null hypothesis that the variable of interest has a regression coefficient equal to zero. To assess its significance, the actual regression coefficient is compared to the distribution of regression coefficients obtained for the bootstrap samples.

Our bootstrap procedure has two important features. First, we sample blocks of 12 subsequent regression residuals $n_{t}$ to accommodate the autocorrelation in the residuals. Second, our procedure accounts for the endogeneity of the regressors $\boldsymbol{X}_{t}$ by sampling new sample paths based on a VAR process. The procedure uses the following steps:

1. Estimate a first-order VAR by OLS on the regressors $\boldsymbol{X}_{t}$ in:

$$
\boldsymbol{X}_{t+1}=\phi_{0}+\boldsymbol{\Phi}_{1} \boldsymbol{X}_{t}+\boldsymbol{\zeta}_{t+1}, \quad \boldsymbol{\eta}_{t} \sim \operatorname{IIDN}\left(0, \boldsymbol{\Sigma}_{\zeta}\right)
$$

Store the estimates $\widehat{\boldsymbol{\phi}}_{0}, \widehat{\boldsymbol{\Phi}}_{1}, \widehat{\boldsymbol{\Sigma}}_{\zeta}$ and calculate the time series of the residuals $\boldsymbol{v}_{t}$. Let $\boldsymbol{L}$ denote the Choleski factorization of $\widehat{\boldsymbol{\Sigma}}_{\zeta}$ such that $\widehat{\boldsymbol{\Sigma}}_{\zeta}=\boldsymbol{L} \boldsymbol{L}^{\prime}$. Store the orthogonalized residuals calculated by:

$$
\boldsymbol{w}_{t}=\boldsymbol{L}^{-1} \boldsymbol{v}_{t}
$$

2. Run the restricted regression in (11) under the null-hypothesis. Store the estimates $\widehat{\alpha}_{0}^{o}$, $\widehat{\boldsymbol{\alpha}}_{1}^{o}$ and the residuals $n_{t}$.

3. Generate an artificial sample $\boldsymbol{w}_{t}^{*}$ by randomly sampling individual elements $w_{i, t}$ with replacement. Subsequently simulate a new sample path $\boldsymbol{X}_{t}^{*}$ of the same length as $\boldsymbol{X}_{t}$ by 
starting with $\boldsymbol{X}_{1}^{*}=\boldsymbol{X}_{1}$ and generating subsequent values by:

$$
\boldsymbol{X}_{t+1}^{*}=\widehat{\phi}_{0}+\widehat{\boldsymbol{\Phi}}_{1} \boldsymbol{X}_{t}^{*}+\boldsymbol{L} \boldsymbol{w}_{t}^{*}
$$

4. Generate an artificial sample of regression residuals $n_{t}^{*}$ by randomly drawing with replacement blocks of 12 subsequent residuals of $n_{t}$. Construct an artificial sample of the dependent variable under the null hypothesis via:

$$
y_{t}^{*}=\widehat{\alpha}_{0}^{o}+\widehat{\boldsymbol{\alpha}}_{1}^{o \prime} \boldsymbol{X}_{t}^{*}+n_{t}^{*} .
$$

5. Run the full regression (11) on the artificial sample $\left(y_{t}^{*}, \boldsymbol{X}_{t}^{*}\right)$ and store the coefficient of interest $\widehat{\alpha}_{1, i}^{*}$.

6. Repeat steps 3-5 10,000 times.

7. Calculate the one-sided bootstrapped $p$-value of $\widehat{\alpha}_{1, i}$ by comparing it to the distribution of the $\widehat{\alpha}_{1, i}^{*}$ for the artificial samples. The $p$-value is calculated as the fraction of $\widehat{\alpha}_{1, i}^{*}$ 's that exceeds $\widehat{\alpha}_{1, i}$.

\section{B Yield Curve Analysis}

\section{A Relation between VAR Model and Bond Return Regressions}

In this section, we establish the link between the VAR model (4) and the system of regression equations (5). Similar to Cochrane and Piazessi (2005), excess bond returns $\boldsymbol{r} \boldsymbol{x}_{t+1}=$ $\left(r x_{t+1}^{(2)}, r x_{t+1}^{(3)}, r x_{t+1}^{(4)}, r x_{t+1}^{(5)}\right)^{\prime}$ are by definition given by:

$$
\left(\begin{array}{l}
r x_{t+1}^{(2)} \\
r x_{t+1}^{(3)} \\
r x_{t+1}^{(4)} \\
r x_{t+1}^{(5)}
\end{array}\right)=-\left(\begin{array}{lllll}
1 & 0 & 0 & 0 & 0 \\
1 & 1 & 0 & 0 & 0 \\
1 & 1 & 1 & 0 & 0 \\
1 & 1 & 1 & 1 & 0
\end{array}\right)\left(\begin{array}{c}
y_{t+1}^{(1)} \\
f_{t+1}^{(2)} \\
f_{t+1}^{(3)} \\
f_{t+1}^{(4)} \\
f_{t+1}^{(5)}
\end{array}\right)+\left(\begin{array}{lllll}
0 & 1 & 0 & 0 & 0 \\
0 & 1 & 1 & 0 & 0 \\
0 & 1 & 1 & 1 & 0 \\
0 & 1 & 1 & 1 & 1
\end{array}\right)\left(\begin{array}{c}
y_{t}^{(1)} \\
f_{t}^{(2)} \\
f_{t}^{(3)} \\
f_{t}^{(4)} \\
f_{t}^{(5)}
\end{array}\right)
$$

or compactly in:

$$
\boldsymbol{r} \boldsymbol{x}_{t+1}=-\boldsymbol{V} \boldsymbol{f}_{t+1}+\boldsymbol{W} \boldsymbol{f}_{t}
$$


Hence $\boldsymbol{z}_{t}=\left(r x_{t}^{(2)}, r x_{t}^{(3)}, r x_{t}^{(4)}, r x_{t}^{(5)}, f_{t}^{(5)}, L N_{t}, D_{12} I L R S M B_{t}\right)^{\prime}$ is given by:

$$
\boldsymbol{z}_{t+1}=\left[\begin{array}{cc}
-\boldsymbol{V} & \mathbf{O}_{3 \times 3} \\
\mathbf{O}_{3 \times 3} & \boldsymbol{I}_{3}
\end{array}\right] \boldsymbol{x}_{t+1}+\left[\begin{array}{cc}
\boldsymbol{W} & \mathbf{O}_{3 \times 3} \\
\mathbf{O}_{3 \times 3} & \boldsymbol{I}_{3}
\end{array}\right] \boldsymbol{x}_{t} \equiv \boldsymbol{M} \boldsymbol{x}_{t+1}+\boldsymbol{N} \boldsymbol{x}_{t}
$$

Substituting the VAR equations in (4) for $\boldsymbol{x}_{t+1}$ and rearranging gives:

$$
\boldsymbol{z}_{t+1}=\boldsymbol{M} \boldsymbol{a}_{x}+\left\{\boldsymbol{M} \boldsymbol{B}_{x}+\boldsymbol{N}\right\} \boldsymbol{x}_{t}\left[\begin{array}{cc}
-\boldsymbol{V} & \mathbf{O}_{3 \times 3} \\
\mathbf{O}_{3 \times 3} & \boldsymbol{I}_{3}
\end{array}\right] \boldsymbol{\nu}_{t+1}
$$

and hence the parameters of the system of regression equations in (5) are linked to the VAR parameters according to:

$$
\begin{aligned}
& \boldsymbol{a}_{z}=\boldsymbol{M} \boldsymbol{a}_{x} \\
& \boldsymbol{B}_{z}=\boldsymbol{M} \boldsymbol{B}_{x}+\boldsymbol{N} \\
& \boldsymbol{\Sigma}_{z}=\boldsymbol{M} \boldsymbol{\Sigma}_{x} \boldsymbol{M}^{\prime} .
\end{aligned}
$$

\section{B The VAR model as a Self-consistent Gaussian Affine Model}

The nominal stochastic discount factor defined in (6) defines a Gaussian affine model. Solving (9) implies that $\log$ bond prices are affine functions of the state variables $\boldsymbol{x}_{t}$. Expressed in terms of forward rates, the solution is given by: $f_{t}^{(n)}=a_{f}(n)+\boldsymbol{b}_{f}(n)^{\prime} \boldsymbol{x}_{t}$, where,

$$
\begin{aligned}
& \boldsymbol{b}_{f}(n)^{\prime}=\boldsymbol{\delta}_{1}^{\prime}\left(\boldsymbol{B}_{x}-\boldsymbol{\Lambda}_{1}\right)^{n-1} \\
& a_{f}(n)=\delta_{0}+\left(\sum_{i=1}^{n-1} \boldsymbol{b}_{f}(i)\right)^{\prime}\left(\boldsymbol{a}_{x}-\boldsymbol{\lambda}_{0}\right)-\frac{1}{2}\left(\sum_{i=1}^{n-1} \boldsymbol{b}_{f}(i)\right)^{\prime} \boldsymbol{\Sigma}_{\nu}\left(\sum_{i=1}^{n-1} \boldsymbol{b}_{f}(i)\right) .
\end{aligned}
$$

The first five elements of the state vector $\boldsymbol{x}_{t}$ are forward rates and hence a self-consistent model must exactly replicate these, which for all $m=1, \ldots, 5$ implies that

$$
a_{f}(m)=0, \quad \text { and } \quad \boldsymbol{b}_{f}(m)=\boldsymbol{e}_{m},
$$

where $\boldsymbol{e}_{m}$ is a 7-dimensional unit vector with the $m$-th element equal to one and all other elements equal to zero. These conditions imply the following restrictions on the parameters of 
the stochastic discount factor:

$$
\begin{aligned}
& \delta_{0}=0, \quad \delta_{1}=e_{1}, \\
& \boldsymbol{e}_{j}^{\prime} \boldsymbol{\Lambda}_{1}=\boldsymbol{e}_{j}^{\prime} \boldsymbol{B}_{x}-\boldsymbol{e}_{j+1}, \quad \boldsymbol{e}_{j}^{\prime} \boldsymbol{\lambda}_{0}=\boldsymbol{e}_{j}^{\prime} \boldsymbol{a}_{x}-\frac{1}{2} \boldsymbol{e}_{j}^{\prime} \boldsymbol{\Sigma}_{\nu}\left(\sum_{i=1}^{j} \boldsymbol{e}_{i}\right), \quad \text { for all } j=1, \ldots, 4 .
\end{aligned}
$$

The restrictions fix $\delta_{0}, \boldsymbol{\delta}_{1}$ and the first four rows of $\boldsymbol{\lambda}_{0}$ and $\boldsymbol{\Lambda}_{1}$. The three remaining rows of $\boldsymbol{\lambda}_{0}$ and $\boldsymbol{\Lambda}_{1}$ are unrestricted and hence the stochastic discount factor is not uniquely pinned down. This stochastic discount factor however exactly reproduces the forward rates in $\boldsymbol{x}_{t}$ and hence there is no indeterminacy for these maturities. 
Table A1

\section{Monthly Bond Portfolio Return Regressions}

The table presents the monthly in-sample forecasting regression of the equally-weighted bond portfolio returns using the CP and LN factors. $\overline{r x}_{m, t+1}=\alpha+\boldsymbol{\beta}^{\prime} \boldsymbol{X}_{t}+\bar{\varepsilon}_{m, t+1} \cdot \overline{r x}_{m}$ is the equally weighted monthly bond excess return, $L N F_{1}-L N F_{9}$ are the Ludvigson and Ng factors, $f^{(1)}-f^{(5)}$ are the one- to five-year forward rates. $C P$ is the Cochrane-Piazzesi factor, a linear combination of the forward rates, and $L N$ is the linear combination of the Ludvigson and $\mathrm{Ng}$ factors. $C P B P$ and $L N B P$ are the linear combination of the Cochrane-Piazzesi and Ludvigson-Ng factors, respectively, constructed for the monthly bond portfolios. The sample period is January 1964 to December 2008. $p$-val is the $p$-value calculated using the Newey-West correction for heteroscedasticity and autocorrelation with 18 lags. $p$-val bst is the bootstrapped $p$-value.

\begin{tabular}{|c|c|c|c|c|c|c|c|c|c|}
\hline & Coef. & p-val & p-val bst & Coef. & p-val & p-val bst & Coef. & p-val & p-val bst \\
\hline Constant & -0.004 & 0.01 & 0.98 & 0.000 & 0.21 & 0.64 & -0.001 & 0.04 & 0.89 \\
\hline$L N F_{1}$ & 0.002 & 0.00 & 0.01 & & & & & & \\
\hline$L N F_{2}$ & 0.002 & 0.04 & 0.01 & & & & & & \\
\hline$L N F_{3}$ & -0.001 & 0.07 & 0.87 & & & & & & \\
\hline$L N F_{4}$ & 0.000 & 0.14 & 0.72 & & & & & & \\
\hline$L N F_{5}$ & -0.002 & 0.00 & 1.00 & & & & & & \\
\hline$L N F_{6}$ & -0.002 & 0.00 & 1.00 & & & & & & \\
\hline$L N F_{7}$ & -0.001 & 0.01 & 0.99 & & & & & & \\
\hline$L N F_{8}$ & 0.002 & 0.00 & 0.00 & & & & & & \\
\hline$L N F_{9}$ & 0.000 & 0.17 & 0.70 & & & & & & \\
\hline$f^{(1)}$ & 0.213 & 0.03 & 0.03 & & & & & & \\
\hline$f^{(2)}$ & -0.200 & 0.04 & 0.88 & & & & & & \\
\hline$f^{(3)}$ & 0.013 & 0.24 & 0.47 & & & & & & \\
\hline$f^{(4)}$ & 0.053 & 0.19 & 0.30 & & & & & & \\
\hline$f^{(5)}$ & 0.004 & 0.24 & 0.48 & & & & & & \\
\hline $\mathrm{CP}$ & & & & 0.020 & 0.15 & 0.19 & & & \\
\hline LN & & & & 0.136 & 0.00 & 0.00 & & & \\
\hline $\mathrm{CPBP}$ & & & & & & & 0.519 & 0.07 & 0.03 \\
\hline LNBP & & & & & & & 0.949 & 0.00 & 0.00 \\
\hline$R^{2}$ & & 0.14 & & & 0.08 & & & 0.13 & \\
\hline Adj. $R^{2}$ & & 0.12 & & & 0.07 & & & 0.12 & \\
\hline
\end{tabular}




\section{Table A2}

\section{Expectations, Bond Risk Premia, and Stock Market Illiquidity}

The table presents the in-sample forecasting regression for the equally-weighted bond portfolio returns using macroeconomic expectations and dispersion of expectations in addition to stock market illiquidity. Panel A presents the regressions without stock market illiquidity, Panel B presents the regressions including $D_{12} I L R S M B$. The factors included are the Cieslak and Povala (2011) factor (Cieslak-Povala) and the dispersions for one quarter and one year expectations for: real GDP ( $R G D P 1 Q, R G D P 1 Y)$, industrial production growth (INDPROD 1Q, INDPROD 1Y), GDP deflator (GDP Deflator 1Q, GDP Deflator $1 Y)$, CPI (CPI 1Q, CPI $1 Y)$, and the difference in the forecast for the 3-month T-bill and 10-year note rates (Tbill-Notes 1Q, Tbill-Notes $1 Y$ ) from the Survey of Professional Forecasters provided by the Philadelphia Fed. $D_{12} I L R S M B$ is the yearly change in the difference of log illiquidity for small and large stocks (small-big). $p$-val is the $p$-value calculated using the Newey-West correction for heteroscedasticity and autocorrelation with 18 lags. All regressions include a constant, not reported to conserve space.

Coef. p-val Coef. p-val Coef. p-val Coef. p-val

Panel A. Expectations and Dispersion of Expectations

\begin{tabular}{lcccccccc}
\hline CP & 0.305 & 0.43 & 0.659 & 0.00 & 0.549 & 0.01 & 0.620 & 0.03 \\
LN & 0.553 & 0.00 & 0.732 & 0.00 & 0.705 & 0.00 & 0.499 & 0.03 \\
Cieslak-Povala & 0.659 & 0.00 & & & & & & \\
RGDP 1Q & & & -0.027 & 0.02 & & & & \\
RGDP 1Y & & & 0.012 & 0.30 & & & & \\
INDPROD 1Q & & & 0.000 & 0.88 & & & & \\
INDPROD 1Y & & & -0.002 & 0.11 & & & & \\
CPI 1Q & & & & -0.010 & 0.36 & & \\
CPI 1Y & & & & 0.050 & 0.00 & & \\
GDP Deflator 1Q & & & & & 0.004 & 0.66 & & \\
GDP Deflator 1Y & & & & & -0.038 & 0.01 & & \\
Tbill-Notes 1Q & & & & & & & 0.032 & 0.00 \\
Tbill-Notes 1Y & & & & & & & 0.004 & 0.76 \\
\hline$R^{2}$ & 0.50 & & 0.42 & & 0.34 & & 0.31 & \\
Adj. $R^{2}$ & 5.50 & & 0.41 & & 0.33 & & 0.30 & \\
\hline Obs & 528 & 471 & & 319 & & 319 & \\
\hline
\end{tabular}

Panel B. Expectations and Dispersion of Expectations with Stock Market Liquidity

\begin{tabular}{lcccccccc}
\hline CP & 0.268 & 0.38 & 0.619 & 0.00 & 0.537 & 0.00 & 0.548 & 0.00 \\
LN & 0.554 & 0.20 & 0.703 & 0.00 & 0.673 & 0.00 & 0.515 & 0.00 \\
$D_{12} I L R S M B$ & 0.017 & 0.01 & 0.023 & 0.00 & 0.019 & 0.02 & 0.020 & 0.03 \\
Cieslack-Povala & 0.641 & 0.11 & & & & & & \\
RGDP 1Q & & & -0.029 & 0.01 & & & & \\
RGDP 1Y & & & 0.011 & 0.18 & & & \\
INDPROD 1Q & & & 0.000 & 0.77 & & & & \\
INDPROD 1Y & & & -0.003 & 0.04 & & & & \\
CPI 1Q & & & & -0.006 & 0.64 & & \\
CPI 1Y & & & & 0.040 & 0.00 & & \\
GDP Deflator 1Q & & & & & 0.006 & 0.39 & & \\
GDP Deflator 1Y & & & & & -0.038 & 0.02 & & \\
Tbill-Notes 1Q & & & & & & & 0.029 & 0.01 \\
Tbill-Notes 1Y & & & & & & 0.005 & 0.73 \\
\hline$R^{2}$ & 0.54 & & 0.48 & & 0.39 & & 0.37 & \\
Adj. R $R^{2}$ & 0.54 & & 0.47 & & 0.38 & & 0.36 & \\
\hline Obs & 528 & & 471 & & 319 & & 319 & \\
\hline
\end{tabular}


Table A3

Futures Market and Stock Market Illiquidity

The table presents monthly regressions of future market variables from Hong and Yogo (2012) and stock market illiquidity. In Panel A the dependent variable is the open interest growth in the bond market (FlowB) and the sample period starts in December 1983. In Panel B the dependent variable is hedging demand imbalance in bond market (ImbalanceB) and the sample period starts in December 1983. In Panel C the dependent variable is open index growth in commodity index (FlowInd) and the sample period starts in December 1965. In Panel D the dependent variable is hedging demand imbalance in commodity index (ImbalanceInd) and the sample period starts in January 1965. In Panel E the dependent variable bond risk premia at $\mathrm{t}+1$. $C P$ denotes the CochranePiazzesi factor. $L N$ is the linear combination of the nine macro factors of Ludvigson and Ng. $D_{12} I L R S M B$ is the yearly change in the log illiquidity difference for small and large stocks (small-big). $p$-val is the $p$-value calculated using the Newey-West correction for heteroscedasticity and autocorrelation with 18 lags. Model $p$-val is the $p$-value for the model specification F-statistic. All regressions include a constant, not reported to conserve space.

\begin{tabular}{|c|c|c|}
\hline Variable & Coef. & Obs \\
\hline
\end{tabular}

Panel A. Open Interest Growth in Bond Market

\begin{tabular}{llllll}
\hline$D_{12} I L R S M B_{t-1}$ & 0.348 & 0.33 & 290 & 0.01 & 0.09 \\
$D_{12} I L R S M B$ & 0.326 & 0.23 & 289 & 0.01 & 0.11 \\
\hline
\end{tabular}

Panel B. Hedgind Demand Imbalance in Bond Market

\begin{tabular}{llllll}
\hline$D_{12} I L R S M B_{t-1}$ & 1.314 & 0.58 & 302 & 0.00 & 0.16 \\
$D_{12} I L R S M B$ & 0.957 & 0.69 & 301 & 0.00 & 0.30 \\
\hline
\end{tabular}

Panel C. Open Index Growth in Commodity Index

\begin{tabular}{llllll}
\hline$D_{12} I L R S M B_{t-1}$ & -0.428 & 0.42 & 483 & 0.01 & 0.04 \\
$D_{12} I L R S M B$ & -0.288 & 0.61 & 482 & 0.00 & 0.18 \\
\hline
\end{tabular}

Panel D. Hedging Demand Imbalance in Commodity Index

\begin{tabular}{llllll}
\hline$D_{12} I L R S M B_{t-1}$ & -5.803 & 0.05 & 506 & 0.03 & 0.00 \\
$D_{12} I L R S M B$ & -4.968 & 0.12 & 505 & 0.02 & 0.00 \\
\hline
\end{tabular}

Panel E. Bond Premia and Futures Information

\begin{tabular}{lrrrr}
\hline Variable & Coef. & p-val & Coef. & p-val \\
\hline CP & 0.680 & 0.00 & 0.799 & 0.00 \\
LN & 0.512 & 0.01 & 0.363 & 0.04 \\
$D_{12} I L R S M B$ & 0.013 & 0.06 & 0.014 & 0.02 \\
FlowInd & -0.001 & 0.77 & & \\
ImbalanceInd & -0.001 & 0.00 & & \\
FlowB & & & -0.001 & 0.71 \\
ImbalanceB & & & 0.001 & 0.03 \\
\hline Obs & 482 & & 289 & \\
Adj. $R^{2}$ & 0.48 & & 0.33 & \\
\hline
\end{tabular}


Table A4

Mutual Fund Bond Flows Correlations

The table presents the monthly correlation in mutual fund flows for the period January 1984 to June 2010. T.E. Money Market are Tax Exempt Money Market flow, Tax. Bond are taxable bond flows. Panel A presents the characteristics of net flows as described in Section VI.D. Panel B presents the characteristics of net exchange flows as described in Section VI.D.

\begin{tabular}{|c|c|c|c|c|c|}
\hline & Equity & Hybrid & $\begin{array}{r}\text { Municipal } \\
\text { Bond }\end{array}$ & $\begin{array}{r}\text { T.E. Money } \\
\text { Market }\end{array}$ & $\begin{array}{r}\text { Taxable } \\
\text { Bond }\end{array}$ \\
\hline \multicolumn{6}{|c|}{ Panel A. Net Flows } \\
\hline Hybrid & 0.57 & & & & \\
\hline Municipal Bond & 0.08 & 0.41 & & & \\
\hline T.E. Money Market & 0.02 & 0.07 & 0.28 & & \\
\hline Taxable Bond & 0.01 & 0.29 & 0.75 & 0.20 & \\
\hline Taxable Money Market & -0.13 & -0.19 & -0.08 & 0.44 & -0.16 \\
\hline \multicolumn{6}{|c|}{ Non-Crisis } \\
\hline Hybrid & 0.58 & & & & \\
\hline Municipal Bond & 0.02 & 0.37 & & & \\
\hline T.E. Money Market & -0.02 & 0.11 & 0.32 & & \\
\hline Taxable Bond & -0.04 & 0.22 & 0.75 & 0.31 & \\
\hline Taxable Money Market & -0.08 & -0.12 & -0.01 & 0.41 & -0.02 \\
\hline \multicolumn{6}{|c|}{ Crisis } \\
\hline Hybrid & 0.42 & & & & \\
\hline Municipal Bond & 0.16 & 0.58 & & & \\
\hline T.E. Money Market & 0.04 & -0.18 & -0.05 & & \\
\hline Taxable Bond & 0.19 & 0.69 & 0.87 & -0.29 & \\
\hline Taxable Money Market & -0.19 & -0.38 & -0.37 & 0.57 & -0.59 \\
\hline \multicolumn{6}{|c|}{ Panel B. Net Exchange Flows } \\
\hline Hybrid & 0.19 & & & & \\
\hline Municipal Bond & 0.24 & 0.15 & & & \\
\hline T.E. Money Market & -0.28 & -0.07 & -0.86 & & \\
\hline Taxable Bond & -0.05 & 0.01 & 0.66 & -0.58 & \\
\hline Taxable Money Market & -0.83 & -0.33 & -0.63 & 0.56 & -0.45 \\
\hline \multicolumn{6}{|c|}{ Non-Crisis } \\
\hline Hybrid & 0.19 & & & & \\
\hline Municipal Bond & 0.26 & 0.18 & & & \\
\hline T.E. Money Market & -0.36 & -0.05 & -0.89 & & \\
\hline Taxable Bond & -0.01 & -0.03 & 0.66 & -0.58 & \\
\hline Taxable Money Market & -0.80 & -0.31 & -0.68 & 0.65 & -0.51 \\
\hline \multicolumn{6}{|c|}{ Crisis } \\
\hline Hybrid & 0.14 & & & & \\
\hline Municipal Bond & 0.31 & 0.19 & & & \\
\hline T.E. Money Market & -0.17 & -0.19 & -0.65 & & \\
\hline Taxable Bond & 0.06 & 0.19 & 0.72 & -0.52 & \\
\hline Taxable Money Market & -0.89 & -0.38 & -0.55 & 0.26 & -0.41 \\
\hline
\end{tabular}




\section{Table A5}

\section{Mutual Fund Bond Flows Characteristics}

The table presents the monthly characteristics of mutual fund flows for the period January 1984 to June 2010. T.E. Money Market are Tax Exempt Money Market flows, Tax. Bond are taxable bond flows. Panel A presents the characteristics of net flows as described in Section VI.D. Panel B presents the characteristics of net exchange flows as described in Section VI.D.

\begin{tabular}{|c|c|c|c|c|c|}
\hline Equity & Hybrid & Municipal & $\begin{array}{r}\text { T.E. } \text { Money } \\
\text { Market }\end{array}$ & $\begin{array}{l}\text { Tax. } \\
\text { Bond }\end{array}$ & $\begin{array}{l}\text { Money } \\
\text { Market }\end{array}$ \\
\hline
\end{tabular}

Panel A. Net Flow

\begin{tabular}{lrrrrrr}
\hline \multicolumn{7}{c}{ Crisis } \\
\hline Mean & 0.00029 & 0.00001 & 0.00012 & 0.00001 & 0.00063 & 0.00088 \\
Median & 0.00065 & 0.00005 & 0.00010 & 0.00010 & 0.00049 & 0.00123 \\
St. Dev. & 0.00185 & 0.00029 & 0.00034 & 0.00094 & 0.00123 & 0.00513 \\
Minimum & -0.00577 & -0.00116 & -0.00103 & -0.00269 & -0.00318 & -0.01171 \\
Maximum & 0.00419 & 0.00097 & 0.00091 & 0.00391 & 0.00347 & 0.01199 \\
Obs. & 71 & 71 & 71 & 71 & 71 & 71 \\
\hline
\end{tabular}

Non Crisis

\begin{tabular}{lrrrrrr}
\hline & & & & & & \\
Mean & 0.00135 & 0.00024 & 0.00032 & 0.00022 & 0.00066 & 0.00042 \\
Median & 0.00123 & 0.00018 & 0.00014 & 0.00020 & 0.00029 & 0.00028 \\
St. Dev. & 0.00148 & 0.00034 & 0.00061 & 0.00097 & 0.00146 & 0.00357 \\
Minimum & -0.00509 & -0.00047 & -0.00187 & -0.00273 & -0.00323 & -0.00990 \\
Maximum & 0.00591 & 0.00179 & 0.00276 & 0.00529 & 0.00591 & 0.01450 \\
Obs. & 245 & 245 & 245 & 245 & 245 & 245 \\
\hline
\end{tabular}

Panel B. Net Exchange

\begin{tabular}{lrrcrrr}
\hline \multicolumn{7}{c}{ Crisis period } \\
\hline Mean & -0.00026 & -0.00003 & 0.00000 & -0.00000 & 0.00009 & 0.00019 \\
Median & -0.00014 & -0.00002 & 0.00001 & 0.00000 & 0.00008 & 0.00002 \\
St. Dev. & 0.00054 & 0.00011 & 0.00012 & 0.00010 & 0.00021 & 0.00066 \\
Minimum & -0.00318 & -0.00029 & -0.00061 & -0.00035 & -0.00088 & -0.00065 \\
Maximum & 0.00070 & 0.00070 & 0.00043 & 0.00036 & 0.00058 & 0.00442 \\
Obs. & 70 & 70 & 70 & 70 & 70 & 70 \\
\hline \multicolumn{7}{c}{} \\
Mean & -0.00002 & -0.00001 & -0.00003 & 0.00003 & -0.00006 & 0.00005 \\
Median & -0.00000 & -0.00001 & -0.00000 & 0.00001 & -0.00003 & 0.00002 \\
St. Dev. & 0.00046 & 0.00006 & 0.00021 & 0.00013 & 0.00027 & 0.00059 \\
Minimum & -0.00219 & -0.00024 & -0.00183 & -0.00025 & -0.00175 & -0.00217 \\
Maximum & 0.00200 & 0.00019 & 0.00045 & 0.00114 & 0.00101 & 0.00273 \\
Obs. & 246 & 246 & 246 & 246 & 246 & \\
\hline
\end{tabular}


Table A6

Bond Term Structure and Flight to Liquidity

The table presents the relation between bond premia for individual maturities, stock market illiquidity, and flight to quality measures. $D_{12} I L R S M B$ is the yearly change in the difference of log illiquidity for small and large stocks (small-big), Funding Liq. is the funding liquidity variable of Fontaine and Garcia (2012), Tax Bond are taxable bond flows, T.E. Money Market are Tax Exempt Money Market flows, Equity are equity flows, and $V X O$ is the S\&P100 volatility index. All mutual fund flows are calculated as net exchange flows, Ben-Rephael et al. (2012). The sample period is January 1986 to December 2007. $p$-val is the $p$-value calculated using the Newey-West correction for heteroscedasticity and autocorrelation with 18 lags.

\begin{tabular}{lrrrrrrrr}
\hline & \multicolumn{2}{c}{2 -year } & \multicolumn{2}{c}{ 3-year } & \multicolumn{2}{c}{ 4-year } & \multicolumn{2}{c}{5 -year } \\
\hline & Coef. & p-val & Coef. & p-val & Coef. & p-val & Coef. & p-val \\
& $(1)$ & $(2)$ & $(3)$ & $(4)$ & $(5)$ & $(6)$ & $(7)$ & $(8)$ \\
\hline C & 0.013 & 0.01 & 0.025 & 0.00 & 0.036 & 0.00 & 0.04 & 0.00 \\
$D_{12}$ ILRSMB & 0.013 & 0.00 & 0.024 & 0.00 & 0.029 & 0.01 & 0.03 & 0.09 \\
Funding Liq. & -0.008 & 0.00 & -0.015 & 0.00 & -0.022 & 0.00 & -0.03 & 0.00 \\
$D_{12}$ ILRSM B*Funding Liq. & -0.01 & 0.05 & -0.011 & 0.04 & -0.014 & 0.03 & -0.01 & 0.05 \\
Tax. Bond & 10.05 & 0.16 & 19.08 & 0.06 & 25.237 & 0.03 & 26.19 & 0.04 \\
TE Money Market & 1.46 & 0.83 & 0.37 & 0.97 & -2.254 & 0.84 & -10.08 & 0.45 \\
Equity Flow & 0.28 & 0.89 & -0.17 & 0.97 & -1.146 & 0.87 & -1.74 & 0.87 \\
VXO & 0.00 & 0.34 & 0.00 & 0.39 & 0.00 & 0.48 & 0.00 & 0.59 \\
\hline$R^{2}$ & 0.25 & 0.25 & 0.23 & 0.20 \\
Adj. $R^{2}$ & 0.23 & 0.23 & 0.21 & 0.18 \\
\hline Obs & 263 & \multicolumn{6}{c}{263} & \multicolumn{6}{c}{263} & \multicolumn{2}{c}{263} \\
\hline
\end{tabular}




\section{References}

Albuquerque, R., E. De Francisco, and L. B. Marques (2008). "Marketwide private information in stocks: Forecasting currency returns." Journal of Finance, 63, 2297-2343.

Amihud, Y. (2002). "Illiquidity and stock returns: cross-section and time-series effects." Journal of Financial Markets, 5, 31-56.

Baele, L., G. Bekaert, and K. Inghelbrecht (2010). "The determinants of stock and bond return comovements." Review of Financial Studies, 23, 2374-2428.

Bailey, W. and R. M. Stulz (1989). "The pricing of stock index options in a general equilibrium model." Journal of Financial and Quantitative Analysis, 24, $1-12$.

Baker, M. and J. C. Stein (2004). "Market liquidity as a sentiment indicator." Journal of Financial Markets, 3, 271-299.

Beber, A., M. Brandt, and K. Kavajecz (2009). "Flightto-quality or flight-to-liquidity? Evidence from the Euro-area bond market." Review of Financial Studies, 22, 925-957.

Bekaert, G., M. Hoerova, and M. L. Duca (2010). "Risk, uncertainty and monetary policy." NBER Working Paper 16397.

Ben-Rephael, A., S. Kandel, and A. Wohl (2012). "Measuring investor sentiment with mutual fund flows." Journal of Financial Economics, 104, 363-382.

Brennan, M., S.-W. Huh, and A. Subrahmanyam (2011). "An analysis of the amihud illiquidity premium." Working Paper.

Brunnermeier, M. K., T. M. Eisenbach, and Y. Sannikov (2012). "Macroeconomics with financial frictions: A survey." In M. A. in D. Acemoglu and E. D. (eds.) (Eds.), "Advances in Economics and Econometrics, 10th World Congress of the Econometric Society," Cambridge University Press, Cambridge, UK.

Brunnermeier, M. K. and L. H. Pedersen (2009). "Market liquidity and funding liquidity." Review of Financial Studies, 22, 2201-2238.

Buraschi, A. and P. Whelan (2012). "Term structure models with differences in beliefs." Imperial College Business School Working Paper.

Campbell, J. and R. Shiller (1991). "Yield spreads and interest rates: A bird's eye view." Review of Economic Studies, 58, 495-514.

Chernov, M. and P. Mueller (2012). "The term structure of inflation expectations." Journal of Financial Economics, 106, 367-394.
Chordia, T., A. Sarkar, and A. Subrahmanyam (2005). "An empirical analysis of stock and bond market liquidity." Review of Financial Studies, 18, 85-129.

Cieslak, A. and P. Povala (2011). "Understanding bond risk premia." Working Paper.

Clark, T. E. and K. D. West (2007). "Approximately normal tests for equal predictive accuracy in nested models." Journal of Econometrics, 138, 291-311.

Cochrane, J. and M. Piazzesi (2005). "Bond risk premia." American Economic Review, 95, 138-160.

Cooper, I. and R. Priestley (2009). "Time-varying risk premiums and the output gap." Review of Financial Studies, 22, 2801-2833.

Diebold, F. X. and R. S. Mariano (1995). "Comparing predictive accuracy." Journal of Business and Economic Statistics, 13, 253-263.

Duffee, G. (2011). "Information in (and not in) the term structure." Review of Financial Studies, 24, $2895-2934$

Duffee, G. (2012). "Bond pricing and the macroeconomy." In M. H. in G. Constantinides and R. S. (eds.) (Eds.), "Handbook of the Economics of Finance," North Holland.

Easley, D., N. M. Kiefer, M. O'Hara, and J. B. Paperman (1996). "Liquidity, information, and infrequently traded stocks." Journal of Finance, 51, 1405-1436.

Eisfeldt, A. L. (2005). "Endogenous liquidity in asset markets." Journal of Finance, 59, 1-30.

Fama, E. and R. Bliss (1987). "The information in long-maturity forward rates." American Economic Review, 77, 680-692.

Ferson, W., S. Sarkissian, and T. Simin (2003). "Spurious regressions in financial economics." Journal of Finance, 58, 1393-1413.

Fleming, M. (2003). "Measuring treasury market liquidity." Economic Policy Review, 9, 83-108.

Fontaine, J.-S. and R. Garcia (2012). "Bond liquidity premia." Review of Financial Studies, 25, 1207-1254.

Gallmeyer, M., B. Hollifield, and D. J. Seppi (2005). "Demand discovery and asset pricing." Carnegie Mellon University Working Paper.

Giacomini, R. and H. White (2006). "Tests of conditional predictive ability." Econometrica, 74, 15451578.

Goldreich, D., B. Hanke, and P. Nath (2005). "The price of future liquidity: Time-varying liquidity in the U.S. treasury market." Review of Finance, 9, $1-32$. 
Goyenko, R., A. Subrahmanyam, and A. Ukhov (2011). "The term structure of bond market liquidity and its implications for expected bond returns." Journal of Financial and Quantitative Analysis, 46, 111-139.

Goyenko, R. Y., C. W. Holden, and C. A. Trzcinka (2009). "Do liquidity measures measure liquidity?" Journal of Financial Economics, 92, 153-181.

Goyenko, R. Y. and A. D. Ukhov (2009). "Stock and bond market liquidity: A long-run empirical analysis." Journal of Financial and Quantitative Analysis, 44, 189-212.

Hong, H. and M. Yogo (2012). "What futures market interest tell us about the macroeconomy and asset prices?" Journal of Financial Economics, 105, 473490.

Huang, J. Z. and Z. Shi (2011). "Determinants of bond risk premia." Penn State Working Paper.

Joslin, S., M. Priebsch, and K. J. Singleton (2010). "Risk premiums in dynamic term structure models with unspanned macro risk." Stanford University Working Paper.

Kiley, M. T. (2008). "Monetary policy actions and longrun inflation expectations." Federal Reserve Board Finance and Economics Discussion Series.

Kiyotaki, N. and J. Moore (2008). "Liquidity, business cycles, and monetary policy." Princeton University Working Paper.

Koijen, R., H. Lustig, and S. V. Nieuwerburgh (2009). "The cross-section and time series of stock and bond returns." Working Paper.

Kyle, A. (1985). "Continuous auctions and insider trading." Econometrica, 53, 1315-1335.

Lesmond, D., J. P. Ogden, and C. A. Trzcinka (1999). "A new estimate of transaction costs." Review of Financial Studies, 12, 1113-1141.
Lettau, M. and J. Wachter (2011). "The term structures of equity and interest rates." Journal of Financial Economics, 101, 90-113.

Li, H., J. Wang, C. Wu, and Y. He (2009). "Are liquidity and information risks priced in the treasury bond market?" Journal of Finance, 64, 467-503.

Longstaff, F. A. (2004). "The flight-to-liquidity premium in U.S. treasury bond prices." Journal of Business, 77, 511-526.

Ludvigson, S. and S. Ng (2009). "Macro factors in bond risk premia." Review of Financial Studies, 22, 50275067 .

Mueller, P., A. Vedolin, and H. Zhou (2011). "Short run bond risk premia." Financial Markets Group Discussion Paper.

Næs, R., J. A. Skjeltorp, and B. A. Ødegaard (2011). "Stock market liquidity and the business cycle." Journal of Finance, 66, 139-176.

Roll, R. (1984). "A simple implicit measure of the effective bid-ask spread in an efficient market." Journal of Finance, 39(4), 1127-1139.

Saar, G. (2006). "Systematic liquidity and learning about the risk premium." Cornell University Working Paper.

Thornton, D. L. and G. Valente (2012). "Out-of-sample predictions of bond excess returns and forward rates: An asset allocation perspective." Review of Financial Studies, 25, 3141-3168.

Warther, V. A. (1995). "Aggregate mutual fund flows and security returns." Journal of Financial Economics, 39, 209-235. 